\title{
NAFLD AND INCREASED RISK OF CARDIOVASCULAR DISEASE: CLINICAL ASSOCIATIONS, PATHOPHYSIOLOGICAL MECHANISMS AND PHARMACOLOGICAL IMPLICATIONS
}

Giovanni Targher ${ }^{1 *}$, Christopher D. Byrne ${ }^{2,3 *}$, Herbert Tilg ${ }^{4 *}$

*All three authors contributed equally to this manuscript

${ }^{1}$ Section of Endocrinology, Diabetes and Metabolism, Department of Medicine, University and Azienda Ospedaliera Universitaria Integrata of Verona, Verona, Italy

${ }^{2}$ Nutrition and Metabolism, Faculty of Medicine, University of Southampton, UK

${ }^{3}$ Southampton National Institute for Health Research Biomedical Research Centre, University Hospital Southampton, Southampton General Hospital, Tremona Road, Southampton, UK

${ }^{4}$ Department of Internal Medicine I, Gastroenterology, Hepatology, Endocrinology \& Metabolism, Medical University Innsbruck, Innsbruck, Austria

Word count: 160 abstract, 7147 text (excluding manuscript title, references and figure legends); Tables: 2,

Figures: 4

LIST OF ABBREVIATIONS: CVD, cardiovascular disease; GCKR, glucokinase regulatory protein; GLP-1 RA, glucagon-like peptide-1 receptor agonist; HCC, hepatocellular carcinoma; IL, interleukin; NAFLD, nonalcoholic fatty liver disease; NASH, nonalcoholic steatohepatitis; PNPLA3, patatin-like phospholipase domaincontaining protein 3; PPAR- $\gamma$, peroxisome proliferator-activated receptor gamma; RCT, randomized controlled trial; T2DM, type 2 diabetes mellitus; TMAO, trimethylamine N-oxide; TM6SF2, trans-membrane 6 superfamily 2 ; TNF- $\alpha$, tumour necrosis factor- $\alpha$; SGLT-2, sodium glucose co-transporter 2

Address for correspondence:

Prof. Giovanni Targher, MD

Section of Endocrinology, Diabetes and Metabolism

University and Azienda Ospedaliera Universitaria Integrata

Piazzale A. Stefani, 1

37126 Verona, Italy

Phone: $+39 / 0458123748$

Fax: $+39 / 0458027314$

E-mail: giovanni.targher@univr.it 


\begin{abstract}
Nonalcoholic fatty liver disease (NAFLD) is a public health problem, affecting up to a third of the world's adult population. Several cohort studies have consistently documented that NAFLD (especially in its more advanced forms) is associated with a higher risk of all-cause mortality and that the leading causes of death among patients with NAFLD are cardiovascular diseases (CVD), followed by extra-hepatic malignancies and liver-related complications. A growing body of evidence also indicates that NAFLD is strongly associated with an increased risk of CVD events and other cardiac complications (i.e. cardiomyopathy, cardiac valvular calcification and cardiac arrhythmias), independently of traditional CVD risk factors. This narrative review provides an overview of the literature on: a) the evidence for an association between NAFLD and increased risk of cardiovascular, cardiac and arrhythmic complications, b) the putative pathophysiological mechanisms linking NAFLD to CVD and other cardiac complications, and c) the current pharmacological treatments for NAFLD that might also benefit or adversely affect risk of CVD.
\end{abstract}




\section{INTRODUCTION}

The 2017 Global Burden of Disease Study showed there were 2.14 million liver-related deaths (2.06 million2.30 million) that year, representing a 11.5\% increase since 2012. Liver cancer and cirrhosis accounted for most of these deaths and, although chronic viral hepatitis remains the commonest cause of liver-related death worldwide, these data show that NAFLD is the most rapidly growing contributor to liver-related mortality and morbidity [1]. In 2016 it was estimated that in the United States, over 64 million people had NAFLD, with annual direct medical costs of about $\$ 103$ billion $(\$ 1,613$ per patient), and in four European countries (France, Germany, Italy and United Kingdom), it was estimated that there were $\sim 52$ million people with NAFLD with an annual cost of about $€ 35$ billion (from $€ 354$ to $€ 1,163$ per patient). Costs of NAFLD were highest in patients aged 45-65 years and it was in this working age group where the economic costs of cardiovascular disease (CVD) were also much higher [2].

CVDs, which include ischaemic heart disease and stroke, are the most common non-communicable diseases globally, responsible for an estimated 17.8 million deaths in 2017, of which more than three quarters were in low-income and middle-income countries [3]. At the global scale, total deaths from CVD increased by nearly $21 \%$ between 2007 and 2017, and were greater for men than for women at most ages in 2017, except for ages $\geq 85$ years where there was the largest female-to-male ratio of CVD deaths [3].

NAFLD occurs in at least $25-30 \%$ of adults in high-income countries and in up to $70-90 \%$ of individuals with obesity or type 2 diabetes mellitus (T2DM) [4]. NAFLD is also an important contributor to morbidity in other organs beyond the liver and, specifically, NAFLD is closely associated with an increased risk of developing extra-hepatic complications, such as CVD, T2DM and chronic kidney disease, with fibrosis stage being the strongest disease-specific risk factor $[5,6,7,8]$.

This review article focuses on the rapidly expanding body of clinical evidence that supports a strong association between NAFLD and the risk of CVD, discusses the pathophysiological mechanisms that link these two conditions and summarizes the pharmacological treatments for NAFLD that might also benefit or adversely affect risk of CVD.

\section{RISK OF CVD AND OTHER CARDIAC COMPLICATIONS}

That NAFLD is associated with an increased risk of CVD is perhaps not surprising, given the close associations of NAFLD with cardiometabolic risk factors encapsulated by the metabolic syndrome, including abdominal obesity, atherogenic dyslipidaemia, hypertension and dysglycaemia $[9,10]$. However, the nature and extent 
of the associations between NAFLD and CVD is not clear. Whether liver disease in NAFLD confers any additional CVD risk, or whether an increase in CVD risk in NAFLD is due to associated CVD risk factors, is uncertain. Elucidating whether liver disease in NAFLD contributes additional CVD risk is important, as it is plausible that treatment of liver disease may ameliorate risk of CVD, over and above treatment of NAFLDassociated risk factors.

Strong evidence links NAFLD with objectively assessed subclinical atherosclerosis (including also increased coronary artery calcium score) in adults and adolescents, as well as with an increased prevalence of clinically manifest CVD both in the general population and in different patient groups $[11,12,13]$. Recently, in a large cohort of South Korean individuals without pre-existing CVD, Lee et al. also showed that imaging-defined NAFLD was independently associated with a higher risk of having non-calcified, "vulnerable" coronary atherosclerotic plaques (as detected by coronary computed tomography angiography), thereby highlighting an increased NAFLD-related CVD risk among these asymptomatic individuals [14].

Several cohort studies have consistently documented that NAFLD is associated with a higher risk of all-cause mortality and that patients with NAFLD are more likely to experience a CVD-related death than a liver-related death $[2,6,9,10]$. Using mortality data from the National Vital Statistics System multiple-cause mortality data in the United States, Paik et al. recently confirmed that CVD was one of the most important causes of death among people with NAFLD [15]. Several cohort studies have also shown that NAFLD (defined radiologically or histologically) is predictive of incident CVD events. Many of these studies were also included in a comprehensive meta-analysis that incorporated a total of 16 observational studies with 34,043 individuals and captured nearly 2,600 major CVD events over a median follow-up of 6.9 years [7]. This metaanalysis concluded that NAFLD (diagnosed by liver biopsy or imaging methods) conferred an odds-ratio of 1.64 for fatal and/or non-fatal CVD events (random-effects odds ratio 1.64, 95\%Cl 1.26-2.13) (Figure 1) [7]. Furthermore, risk of incident CVD events appeared to increase further with greater severity of NAFLD (random-effects odds ratio $2.58 ; 95 \% \mathrm{Cl} 1.78-3.75$ ) (Figure 2), and remained statistically significant in those studies where analysis was fully adjusted for established CVD risk factors [7].

Although further studies in patients with biopsy-characterised NAFLD are needed to address this issue, some prospective studies with sufficiently long follow-ups have confirmed that the magnitude of risk of incident CVD paralleled the underlying severity of NAFLD and that fibrosis stage, rather than other histologic features of NAFLD, were independently associated with adverse CVD and liver-related outcomes $[16,17]$. Recently, in a multinational cohort study of 458 adults with biopsy-confirmed NAFLD with advanced fibrosis or compensated cirrhosis, Vilar-Gomez et al. found that patients with advanced fibrosis had predominantly CVD 
events and extra-hepatic cancers, and those with NAFLD-cirrhosis had predominantly liver-related events, over a mean follow-up of 5.5 years [18]. In a cohort of 285 United States adults with biopsy-proven NAFLD without pre-existing CVD, Henson et al. found that advanced fibrosis, but no other histologic features of NAFLD, were associated with increased CVD incidence over a median of 5.2 years, even after adjusting for traditional risk factors and CVD risk scores [19]. Conversely, in a large case-control study, Hagström et al. found that 603 Swedish individuals with biopsy-proven NAFLD free of baseline CVD were at higher risk of incident CVD events compared to age- and sex-matched controls, although histologic features of NAFLD did not significantly predict risk of CVD events over a mean follow-up of 18.6 years [20].

Other large studies recently showed that NAFLD was independently associated with an increased incidence of acute myocardial infarction, even in primary care populations [21, 22]. However, this latter finding has recently been questioned in a population-based case-control study that failed to find any significant association between a recorded diagnosis of NAFLD and risk of developing myocardial infarction and stroke, after adjustment for traditional CVD risk factors, using electronic records from four large European primary healthcare databases [23]. However, the lack of any independent association between NAFLD and risk of acute myocardial infarction and stroke reported in this study [23] may not be because such an association does not exist; but it is probably due to misclassification bias of NAFLD cases and other important methodological issues within the study design [24].

It is worth noting that some observational cohort studies, mostly performed in Asian populations, have reported that there is a significant and independent association between NAFLD and long-term risk of progression of subclinical coronary or carotid atherosclerosis, and, most importantly, that regression of NAFLD on ultrasonography over time is associated with a lower risk of carotid atherosclerosis development $[25,26]$.

Finally, convincing evidence also indicates that NAFLD is strongly associated with valvular heart disease (mainly aortic-valve sclerosis and mitral annulus calcification), increased risk of cardiomyopathy (mainly left ventricular dysfunction and hypertrophy, leading to the development of heart failure), arrhythmias (mainly permanent atrial fibrillation and increased QTc interval prolongation) and some cardiac conduction defects (mainly persistent first-degree atrio-ventricular block and left anterior hemi-block) [27, 28].

Collectively, the available evidence not only demonstrates the strong association between NAFLD and CVD but also supports the view that NAFLD may increase risk of incident CVD events. These findings may have 
important implications for decision making in public health and clinical practice, and highlight the urgency of developing effective treatments for NAFLD. On this background of evidence, the European (EASL-EASD-EASO) and American (AASLD) society guidelines for the management of NAFLD strongly recommended that all patients with NAFLD should undergo careful cardiovascular surveillance $[29,30]$. To this end, a possible strategy at least in adults with NAFLD on primary CVD prevention might be to rely on the use of the Framingham risk score or other risk charts for CVD risk assessment [29, 30, 31, 32]. Although the Framingham risk score has been validated for use in NAFLD patients $[33,34]$, it remains to be demonstrated whether addition of NAFLD improves the accuracy of risk score systems to predict CVD events. Moreover, large randomized controlled trials (RCTs) with CVD outcomes that focus on treatments for liver disease in NAFLD are also needed to better establish a causal relationship between treatment of NAFLD and effects of improvements in liver disease on incident CVD events. Despite tremendous research advancements in NAFLD, our understanding of sex differences in NAFLD remains insufficient [35]. It is known that CVD and NAFLD are both modulated by advancing age, sex, reproductive stage (i.e. menopausal status) and synthetic hormone use $[3,36,37,38,39]$. Recent evidence also suggests that women with NAFLD lose the CVD protection conferred by the female sex, and their global risk is underestimated by current CVD risk score systems [40]. An adequate consideration of age, sex differences, sex hormones/menopausal status and other reproductive information in clinical investigation and gene association studies of NAFLD will be required to fill current gaps and implement precision medicine for NAFLD patients [35]. In the meantime, also in accord with the AASLD clinical guidelines, we strongly recommend that aggressive modification of coexisting cardiometabolic risk factors should be considered in all patients with NAFLD as these patients are at high risk for CVD mortality and morbidity [30].

\section{MECHANISMS LINKING NAFLD TO CVD AND OTHER CARDIAC COMPLICATIONS}

The pathophysiology behind the association of NAFLD with CVD and other cardiac complications is incompletely understood and may involve other pathways besides insulin resistance, e.g. low-grade inflammation, oxidative stress and the effects of perturbations in the gut microbiota (Figure 3) [41]. Lowgrade inflammation is a key feature of many metabolic diseases, such as T2DM, obesity and related disorders including NAFLD. NAFLD is not only linked to CVD and T2DM, but also to chronic kidney disease [10]. Importantly, these associations are especially relevant in patients with NASH, suggesting that liver inflammation may directly contribute to the development of these extra-hepatic diseases.

\section{Multiple sources of cytokines drive liver inflammation and extra-hepatic complications}

Whereas it is recognized that liver fibrosis determines long-term liver prognosis in NAFLD, it is generally accepted that liver inflammation precedes fibrosis in most instances. However, hepatic fat accumulation may 
also lead to liver damage, i.e. fibrosis, independent from inflammation [42]. In addition, it is well recognized that advanced disease (i.e. fibrosis stage $3-4$ ) is characterized by hepatic fat loss and less inflammation but increased adiponectin levels potentially contributing to this phenotype [43]. Importantly, liver inflammation is accompanied by hepatic accumulation of inflammatory leukocytes and increased hepatic and extra-hepatic cytokine production $[44,45]$. It has also to be acknowledged that inflammation might be present in the liver intermittently and/or in a chronic-relapsing manner. This could also explain why liver fibrosis might play a role in CVD development [46]. Many pre-clinical and clinical studies have shown that blockade of proinflammatory cytokines, such as interleukin (IL)-11, not only attenuates steatosis but also liver inflammation and fibrosis development [47]. Although various sites of cytokine production are assumed, such as the liver, adipose tissue and gastrointestinal tract, it remains unclear how much each compartment contributes to overall inflammation observed in NAFLD. The "multiple-hits" hypothesis proposed a decade ago highlighted these different compartments as sources of cytokine production [44].

Various lipid-related pathways may "drive" hepatic inflammatory pathways in NAFLD [48, 49]. Whereas it had been initially believed that mainly intrahepatic triglyceride accumulation might contribute to liver inflammation, several studies have highlighted other pathways that may increase inflammation. These include enzymes involved in fatty acid synthesis, certain sphingolipids and polyunsaturated-derived eicosanoids, and specialized pro-resolving lipid mediators [50]. Saturated fat induces more pronounced increases in intrahepatic triglyceride content and insulin resistance compared to unsaturated fat and simple sugars [51]. Plasma lipids might also be disease relevant as shown for certain ceramides which concentrations were independently associated with greater severity of coronary artery stenosis in the left anterior descending artery [52]. Mitochondrial dysfunction and endoplasmic reticulum stress activation are also key factors contributing to NAFLD and insulin resistance [53]. Reducing endoplasmic reticulum stress by lipid chaperones reduces atherosclerosis, a key component in the clinical presentation of NAFLD [54].

A link between dyslipidaemia and hepatic inflammation has also been suggested by recent data showing that proprotein convertase subtilisin/kexin type-7 (PCSK7) gene variations correlate with severity of liver disease in human NAFLD [55]. Furthermore, the presence of liver fat has also been linked to plasma inflammatory biomarkers in the Framingham Heart Study [56]. Extracellular vesicles released by steatotic hepatocytes are also able to drive endothelial inflammation and atherogenesis [57]. These vesicles are characterized by altered miRNA expression profiles facilitating vascular inflammation by miR-1 release and NF- $\mathrm{KB}$ activation [57]. Besides the importance of pathways in adipose tissue, plasma lipids appear to be of crucial relevance in the association between NAFLD and CVD risk [58]. Certain genetic variants associated with NAFLD, such as the patatin-like phospholipase domain-containing protein 3 (PNPLA3) and the trans-membrane 6 superfamily 
2 (TM6SF2) gene variants may protect against CVD risk and variants in glucokinase regulatory protein (GCKR) may be associated with increased CVD risk, perhaps mediated by a decrease in the atherogenic dyslipidaemic lipid profile in both PNPLA3 and TM6SF2 carriers and increase in the atherogenic dyslipidaemic profile in GCKR carriers [58]. However, further research is needed to better understand whether "genetic-related NAFLD" and "metabolic-related NAFLD" may exert differential effects on risk of incident CVD events [10, 59].

Expanded visceral adipose tissue is a major site of low-grade inflammation in NAFLD. Increased plasma IL-6 concentrations have also been associated with subclinical atherosclerosis in population-based studies [60], and earlier studies have shown that visceral adipose tissue contributes at least $35 \%$ of circulating levels of IL6, a major pro-inflammatory cytokine in obesity-related disorders that is mainly responsible for increased plasma C-reactive protein levels [61]. Visceral adipose tissue also expresses much higher concentrations of IL-6, IL-1 $\beta$ and tumour necrosis factor (TNF)- $\alpha$ compared to the liver and profound weight loss almost eliminates this expression, especially in adipose tissue $[62,63]$. Expanded visceral adipose tissue might also affect NAFLD not only via the secretion of pro-inflammatory mediators as pharmacological inhibition of adipose triglyceride lipase by atglistatin inhibits high-fat diet induced insulin resistance and NAFLD [64], establishing also a non-inflammatory 'adipose tissue-liver' axis.

\section{Proinflammatory pathways targeting vessels and the heart in NAFLD}

Ectopic fat depots in the epicardium, pericardium and myocardium are associated with NAFLD and characterized by distinct metabolic signatures as demonstrated by magnetic resonance spectroscopy [65]. To date, it is not known whether pro-inflammatory pathways in ectopic fat directly affect cardiac function and atherosclerosis development. In systemic inflammatory diseases such as rheumatoid arthritis, there is an increased risk of sudden cardiac death and arrhythmias [66], and macrophage-derived IL-1 $\beta$ induces arrhythmias in diabetic mice [67]. A meta-analysis has shown that increased pro-inflammatory biomarkers, such as plasma IL-6 and C-reactive protein levels, are associated with an increased incidence of atrial fibrillation [68], and whether decreasing pro-inflammatory biomarkers with a targeted anti-inflammatory agent reduces risk of CVD events has been tested in the CANTOS trial [69]. In this proof-of-concept RCT, treatment with canakinumab (i.e. an anti-IL-1 $\beta$ monoclonal antibody) led to a lower rate of recurrent CVD events than placebo, independent of lipid-level lowering [69]. Also other pro-inflammatory cytokines, such as TNF- $\alpha$ and IL-17, have the capability, at least in pre-clinical studies, to induce cardiac arrhythmias [70]. Intense physical endurance induced atrial arrhythmia susceptibility in rats, via a TNF $\alpha$-dependent mechanism [71]. IL-17, another pro-inflammatory cytokine, contributes to ischemia-induced arrhythmias in rabbits [72], and IL-1 $\beta$, TNF $\alpha$ and IL- 6 contribute to arrhythmias in rats [73]. 


\section{NAFLD, microbiome and low-grade inflammation}

There is increasing evidence that the gut microbiota controls metabolic functions and is involved in NAFLD pathogenesis. Early animal experiments suggested that the gut microbiota is crucial for development of adipose tissue [74] and evolution of NAFLD [75]. A potential role for the intestinal microbiota in human NAFLD has been recently presented [76]. Advanced liver fibrosis was associated with an increased abundance of Proteobacteria and $E$. coli and a decrease in Firmicutes. Interestingly, a gut microbiome specific signature has been demonstrated in NAFLD-related cirrhosis, [77]. Also in children an inflammation-related and fibrosisrelated gut microbiome signature was observed with high presence of Prevotella copri [78]. At a species level, concentrations of Ruminococcus, Blautia and Dorea were increased in NASH patients [79]. A profound intestinal dysbiosis has also been observed in NAFLD that is independent of obesity and insulin resistance [80]. Faecalibacterium prausnitzii, a well-defined anti-inflammatory bacterial strain, was substantially decreased in NAFLD patients [81] and substantial changes in the gut microbiome with a decrease in Collinsella and Parabacteroides have been observed in NAFLD-associated coronary heart disease [82].

The gut microbiota affects substantially circulating metabolites in NAFLD [83]. Phenylacetate is associated with hepatic steatosis and faecal transfer from obese women with high-grade steatosis into mice resulted in hepatic steatosis, as did feeding phenylacetate to mice [83]. Other gut-derived metabolites might be involved in NAFLD pathogenesis [84]. 3-(4-hydroxyphenyl)-lactate, mainly derived from Proteobacteria, was associated (in two independent patient cohorts) with hepatic steatosis and degree of fibrosis [84]. Bacterial components may also be present in the livers in NAFLD, as a meta-taxonomic signature and also increased endotoxin has been detected in the livers $[85,86]$. All these studies support a role for intestinal microbiota in NAFLD pathogenesis and hold the promise that manipulation at this level might improve liver disease phenotype. That said, to date, it remains uncertain what prebiotics, probiotics or synbiotics should be used to change the gut microbiota. Moreover, it is not known which gut microbiota need to be modified, both in type and in quantity, in order to benefit the liver and/or CVD risk in NAFLD. A recent phase 2 RCT tested whether 1-year administration of a synbiotic combination of probiotic and prebiotic agents affected hepatic fat content (assessed by magnetic resonance spectroscopy), non-invasive fibrosis biomarkers, and the composition of the faecal microbiome in 104 UK patients with NAFLD. The results of this RCT showed that the synbiotic altered the faecal microbiome, but did not reduce hepatic fat content or biomarkers of liver fibrosis. Faecal samples from patients, who received the synbiotic, had higher proportions of Bifidobacterium and Faecalibacterium, and reductions in Oscillibacter and Alistipes, compared with baseline (changes were not observed in the placebo group) [87]. 
Gut microbes and related metabolites have been recently discovered as potentially important players in CVD. Commensals convert certain nutrients such as choline or carnitine into trimethylamine (TMA), which is metabolized in the liver by flavin mono-oxygenases to TMA N-oxide (TMAO). L-carnitine enriched diet in humans is converted into TMAO, an effect which was less pronounced in vegans/vegetarians [88]. This has also been observed after chronic red meat consumption and, interestingly, discontinuation of red meat consumption reduced TMAO levels within four weeks [89].

Many studies have shown that higher circulating TMAO levels are associated with adverse CVD outcomes $[90,91]$. Furthermore, some meta-analyses have also confirmed a strong association between circulating TMAO levels and risk of fatal and non-fatal CVD events [92, 93]. Patients with ischaemic stroke also exhibit higher TMAO levels than healthy controls [94], and increased TMAO levels also predict CVD mortality in patients with existing peripheral arterial disease [95]. Interestingly, so far only a very few reports exist investigating circulating TMAO levels in NAFLD cohorts. In a study assessing 60 biopsy-proven NAFLD subjects, a greater severity of NAFLD was associated with higher TMAO levels but lower betaine and betaine/choline ratio [96]. Despite the shortage of reports on TMAO in NAFLD, it is increasingly accepted that circulating TMAO levels are a prominent biomarker of CVD, which is the most common cause of mortality in NAFLD patients. In addition, an association with thrombosis events was both shown clinically and experimentally as TMAO alters calcium signalling in platelets, and enhances responsiveness and in-vivo thrombosis potential in various animal models [97]. Inhibitors of TMA-generating enzymes significantly reduced plasma TMAO levels for up to three days and rescued diet-induced enhanced platelet responsiveness and thrombus formation [98]. Another study observed a U-shaped association between TMAO levels and mortality risk in patients with acute venous thromboembolism, but it was not associated with recurrent venous thromboembolism [99].

The explanation as to how elevated TMAO levels might increase risk of CVD/cardiac complications is uncertain. A recent study found that TMAO affects the cardiac autonomic nervous system, promoting ischemia-induced ventricular arrhythmias [100]. Another mode of action might involve the endoplasmic reticulum stress kinase PERK. PERK is a receptor for TMAO, and its binding results in PERK activation and induction of the transcription factor FoxO1, a key factor in metabolic disorders [101]. Interestingly, TMAO may directly activate pro-inflammatory pathways as it up-regulates NLRP3 and nuclear factor (NF)-KB and thereby promotes vascular calcification [102]. Thus, TMAO reflects a crucial microbiota-derived biomarker of atherosclerosis and potentially of NAFLD-associated CVD. 
The cornerstone of NAFLD management remains lifestyle modification. Weight loss, increased physical activity, and reductions in coexisting cardiometabolic risk factors may all have beneficial effects in NAFLD. Weight loss of approximately $5-7 \%$ is able to decrease hepatic steatosis; however, an approximate $10 \%$ weight loss is required to reverse NASH and weight loss of $\geq 10 \%$ may also improve or reverse hepatic fibrosis $[29,30]$. Additionally, bariatric or weight loss surgery has been shown to ameliorate many CVD risk factors and may also be directly beneficial in patients with early liver disease. However, it is beyond the remit of this review to discuss the metabolic and vascular benefits of bariatric surgery in NAFLD and the reader is referred to recent clinical practice guidelines for the perioperative nutrition, metabolic and non-surgical support of patients undergoing bariatric procedures [103].

Presently, there are no approved pharmacological treatments for NAFLD or NASH. From a recent systematic review, it clearly emerges that the major issue in this field is the scarcity of high-quality, adequately powered RCTs of sufficient duration that include clinically relevant hepatic endpoints (i.e. liver histologic data) [104]. However, there are several novel therapeutic agents under active investigation, and a variety of other drugs will also likely emerge over the next few years, allowing a more staged approach to the management of NAFLD that is likely to vary from patient to patient. That said, in selecting a specific drug for the treatment of NAFLD, we believe that pharmacologic treatments should be chosen that target not only liver-related complications (cirrhosis and hepatocellular carcinoma [HCC]) but also the increased CVD risk in NAFLD [105]. Additionally, since NAFLD is a risk factor for incident T2DM [106] (which is also a risk factor for CVD), the ideal treatment for NAFLD would not only ameliorate liver disease, but also attenuate risk of developing T2DM [107], and thereby consequently lessen the risk of CVD.

It is beyond the scope of this review to discuss the evidence for all drugs that have been tested in the treatment of NAFLD. Therefore, we have focused on drug treatment options that might benefit not only the liver but also have beneficial (or adverse effects) on NAFLD-associated CVD risk. As discussed above, there is also a growing interest in the role of dysbiosis in both the pathogenesis of NAFLD and CVD. Whether faecal transplantation [108] to improve the gut microbiota profile and drugs relevant to the treatment of NASH, can favourably affect: gut microbiota; modify intestinal permeability and intestinal functions; and thereby treat NAFLD and CVD, remains uncertain. Presently, it is not known whether faecal transplantion benefits NAFLD. However, a recent pilot in which 20 men with metabolic syndrome were randomized to single lean vegandonor or autologous faecal microbiota transplantation, caused detectable changes in intestinal microbiota composition, but failed to induce changes in TMAO production capacity or parameters related to vascular inflammation [109]. 
We have also briefly discussed below the evidence to date showing whether (or not) drugs relevant to the treatment of NAFLD and CVD can affect the gut microbiota, or gut microbiota-related mechanisms relevant to liver and vascular diseases.

\section{Pioglitazone}

The discovery of peroxisome proliferator-activated receptor gamma (PPAR- $\gamma$ ) in adipose tissue produced a step change in adipose tissue research [110]. PPARs are a group of nuclear receptor proteins that function as transcription regulators and PPAR- $\gamma$ heterodimerises with retinoid $X$ receptor and binds to specific DNA sequences to regulate adipocyte differentiation and function, lipid metabolism and inflammation [111]. Glitazones (e.g. rosiglitazone and pioglitazone) are selective activators of PPAR- - and pioglitazone is a potent insulin sensitizer that is currently licensed for treatment of T2DM. Although there are well-recognised side effects of pioglitazone, such as a mild increase in body weight (especially subcutaneous fat depots), fluid retention (oedema and heart failure) and an increase in fragility fractures, there are also many benefits of pioglitazone besides its very durable effect to reduce plasma glucose concentrations in people with T2DM.

Since NAFLD independently increases risk of incident T2DM by 2.2 fold [106] and pioglitazone decreases risk of incident T2DM in individuals with prediabetes [112], it is reasonable to assume that pioglitazone may also decrease risk of incident T2DM in patients with NAFLD. Moreover, NAFLD increases risk of hypertension [113], a recognised CVD risk factor, and pioglitazone lowers blood pressure [112]. NAFLD is an independent risk factor for CVD [7] and both ischaemic heart disease and stroke are two of the leading causes of death worldwide. T2DM also increases risk of major CVD events two fold $[114,115,116]$ and pioglitazone has been shown in the PROactive trial (PROspective pioglitAzone Clinical Trial In macroVascular Events) to decrease the composite of all-cause mortality, non-fatal myocardial infarction or stroke in T2DM patients with macrovascular disease [117]. In this RCT, pioglitazone use was also associated with a $28 \%$ decrease in myocardial infarction [118] and a $47 \%$ decrease in ischaemic stroke [119]. In support of these findings, a meta-analysis of 19 RCTs enrolling 16,500 patients showed a summary estimate of an $18 \%$ decrease in the composite of all-cause mortality, myocardial infarction or stroke (hazard ratio [HR] 0.82; $95 \% \mathrm{Cl} 0.72-0.94$ ) with pioglitazone treatment [120]. Another meta-analysis investigating the effect of pioglitazone on risk of CVD events showed a benefit with pioglitazone in both patients with prediabetes (or insulin resistance) and those with T2DM [121]. Recent evidence also showed that pioglitazone decreased risk of stroke or myocardial infarction in patients without T2DM but with insulin resistance after previous stroke or transient ischaemic attack $[122,123]$. A large umbrella review recently confirmed that pioglitazone significantly decreased risk of major CVD events but increased risk of heart failure [124]. 
Pioglitazone treatment has been tested in several placebo-controlled RCTs in patients with biopsy-confirmed NASH and pioglitazone treatment resulted in improvement in histologic features of NAFLD and resolution of NASH in $~ 50 \%$ of patients; regardless of diabetes status $[125,126,127,128]$. Interestingly, a meta-analysis of eight RCTs (including a total of 516 adults with biopsy-confirmed NASH) showed that pioglitazone improved advanced fibrosis in NASH, even in patients without diabetes [129]. Although the PPAR- $\gamma 2$ isoform is highly expressed in adipocytes, PPAR- $\gamma 1$ isoform is also expressed in hepatic stellate cells and Kupffer cells. Pioglitazone effects on the liver are likely mediated by a combination of indirect effects on the adipose tissue to decrease free fatty acid flux to the liver and increase adiponectin levels (resulting in improved hepatic steatosis); and a direct effect of the drug on both Kupffer cells and stellate cells to decrease hepatic inflammation and fibrogenesis. Based on the available evidence, three sets of guidelines from the UK, Europe and USA have strongly recommended pioglitazone for treatment of NASH $[29,30,130]$.

Although presently it is not possible to predict which NASH patients are going to achieve NASH resolution with pioglitazone use, a recent post-hoc analysis of the PIVENS trial [126] suggested that after treatment with pioglitazone, patients with histological resolution of NASH had favourable changes in lipoprotein subfractions compared to those without NASH resolution. In fact, individuals with NASH resolution had a significantly increased mean peak LDL diameter and a higher frequency of LDL phenotype A (i.e. large buoyant LDL particles) at week 96, even after adjustment for relevant confounding factors, including treatment group [131].

To date, there is limited data regarding whether pioglitazone use may affect the gut microbiota. However, the PPAR- $\psi$ receptor is a butyrate sensor in the colonic lumen [132], and microbiota-activated PPAR- $\gamma$ signaling has been reported to prevent dysbiotic expansion of pathogenic bacteria by driving the energy metabolism of colonic epithelial cells [133]. In a mouse model of dietary fructose-driven gut dysbiosis that caused intestinal epithelial barrier impairment [134], the authors showed that pioglitazone repaired intestinal epithelial barrier damage by activating the NOD-like receptor family pyrin domain-containing 6 (NLRP6) inflammasome. Thus, it is possible that pioglitazone treatment could decrease the inflammatory stimulus from lipopolysaccaride breaching the intestinal epithelial barrier, and gaining access to the portal circulation.

Such is the wealth of evidence supporting its effectiveness in decreasing risk of incident T2DM, treating hyperglycaemia in T2DM and decreasing risk of major CVD events, pioglitazone has been recently described as the "forgotten, cost-effective, cardio-protective" drug for T2DM [135]. Given the evidence described above 
supporting its use in the treatment of liver disease in NASH, the overall evidence supports its use in NASH assuming there are no contradictions to treatment with pioglitazone. Few drugs are free of side effects and clinicians need to weigh up the balance of risk and benefits of prescribing this drug in their individual patients with NASH. Figure 4 schematically shows the inter-relationships between NAFLD, T2DM and CVD and where RCTs have shown pioglitazone treatment acts to significantly decrease risk of clinical outcomes in each condition. Were it not for the fact that pioglitazone treatment is associated with an increased risk of weight gain, and a small increase in bone fracture risk, pioglitazone treatment would be much more widely used in treating patients with NASH.

\section{Statins}

There is limited high-quality data with histological liver endpoints showing that statin use improves NASH [136]. There is also limited data regarding whether statin use affects the gut microbiota. That said, it has been suggested that the modulation of gut microbiota by statins has an important role in the therapeutic actions of these drugs [137], and these authors also suggested that faecal microbiota transplantation also improved plasma glucose concentrations. In this study using a mouse model of high-fat diet-induced obesity, the association between gut microbiota and immune responses was investigated. Both atorvastatin and rosuvastatin increased the abundance of the genera Bacteroides, Butyricimonas, and Mucispirillum. The abundance of these genera was correlated with the inflammatory response, including levels of IL-1 $\beta$ and transforming growth factor- $\beta 1$ in the ileum. In addition, oral faecal microbiota transplantation with faecal material collected from rosuvastatin-treated mouse groups improved hyperglycaemia. Additionally, a proofof-concept study in individuals with dyslipidemia showed that 4 to 8 weeks of rosuvastatin treatment significantly altered the gut microbiome and the abundance of specific bacterial taxa, which was correlated with the LDL-cholesterol-lowering response of the drug [138]. In this study, both Firmicutes and Fusobacteria were inversely associated with plasma LDL-cholesterol concentrations, whilst Cyanobacteria and Lentisphaerae were positively associated with LDL-cholesterol concentrations. However, it is important to note that this study lacked a control group, and the bacterial sequencing was performed only after rosuvastatin treatment. Consequently, the authors did not investigate the changes in the gut microbiome. Finally, it has also been suggested that gut microbiota may interact with statin treatments to both modify farnesoid $X$ receptor signalling and decrease statin bioavailability, thereby potentially producing physiologically relevant effects on liver lipid and glucose metabolism [139].

A recent Expert Panel Statement concluded that the evidence from: animal studies, five post-hoc analyses of prospective long-term survival studies, and five rather small biopsy-proven NASH studies that investigated the effect of statins on the liver in NAFLD, was not good enough to recommend statin treatment specifically 
for treating liver disease in NAFLD [140]. Notably, these studies provided data that suggested biochemical and histological improvement of NAFLD/NASH with statins and, in the clinical studies, large reductions in CVD events in patients with NAFLD compared to those who did not have NAFLD [140]. Recently, there has also been interest in whether statins specifically decrease risk of liver fibrosis. In a cross-sectional study of 346 individuals with T2DM of which $45 \%$ were taking statins, multivariate analyses showed that statin use was inversely associated with significant liver fibrosis, despite statin-treated patients being older, more frequently male and with poorer glycaemic control than those without statins [141]. However, it should be noted that to date, none of the available evidence is from RCTs that have tested the prior hypothesis that statins decrease liver fibrosis. Thus, the evidence is currently not good enough to recommend statin usage in order to specifically treat NAFLD or NASH. Nevertheless, pending forthcoming RCTs, clinicians should consider combining statins and pioglitazone in those patients with NAFLD or NASH, who are at high risk of CVD, for the primary and secondary prevention of CVD [140].

Currently, the American College of Cardiology/American Heart Association guidelines for primary CVD prevention recommend statin use as a first-line treatment in patients with increased plasma LDL-cholesterol concentrations (LDL-cholesterol $\geq 5 \mathrm{mmol} / \mathrm{L}$ ); those with T2DM, who are 40 to 75 years of age; and those determined to be at 'sufficient' CVD risk [142]. Presently, there is disagreement between different professional societies as to what constitutes 'sufficient' CVD risk (to prescribe statins), but in the above guidelines 'sufficient' CVD risk is defined as $\geq 7.5 \%$ risk of developing a CVD event over 10 years. Although the CVD risk threshold that is required to advocate statin treatment has been lowered considerably over the last 20 years, most professional societies would endorse statin treatment when the patient's 10-year CVD risk estimation was $\geq 10 \%$.

For estimating CVD risk in NAFLD patients, there are no specific CVD risk prediction tools that take into account the presence or severity of NAFLD. To date, there is insufficient evidence to gauge whether knowing the patient has a diagnosis of NAFLD (with or without accompanying fibrosis) adds to existing risk factors in CVD risk estimation. Consequently, rather than recommending any specific CVD risk calculator, e.g. the Framingham risk score or the SCORE (Systematic Coronary Risk Estimation) charts, it is better that a clinician uses a risk calculator than not. Given that the evidence discussed above suggests that NAFLD is a risk factor for CVD, it is highly likely that prediction of 10-year CVD risk in NAFLD is an underestimate of true CVD risk. Consequently, since statins are safe in patients with NAFLD [143], it would seem logical to err on the side of caution, and advocate use of statins to decrease CVD risk when the 10-year CVD risk is $\geq 7.5 \%$. There is also some, more limited, evidence that statin treatment is associated with a reduced risk of HCC, most strongly in 
Asian but also in Western populations [144]. However, RCTs with statin treatment are required in populations at high risk of HCC, before advocating this treatment specifically to attenuate risk of HCC.

\section{Metformin and other newer anti-hyperglycaemic agents}

Metformin represents the first-line choice for treatment of T2DM worldwide. However, metformin is not currently recommended as a specific treatment for NAFLD or NASH, mostly due to its lack of efficacy on hepatic histological endpoints in both adults and adolescents with biopsy-confirmed NASH, irrespective of diabetes status $[29,30,104]$. To date, there remains uncertainty about whether metformin reduces risk of major CVD events $[124,145]$. Interestingly, however, several pre-clinical and observational studies and recent meta-analyses suggest that metformin reduces risk of developing some types of cancer, especially HCC [146, 147]. It has also become well accepted that metformin has favourable effects on the intestinal microbiome. Metformin treatment increases microbial diversity and specifically increases mucin-degrading Akkermansia muciniphila, as well as several short-chain fatty acid-producing microbiota, increasing levels of butyrate and propionate that are involved in both glucose homeostasis and maintaining colonic epithelial integrity [148, 149].

Similar to metformin, no robust RCT data exist with histological liver endpoints as a primary outcome to formally comment on the effectiveness of the use of the newer anti-hyperglycaemic agents, such as dipeptidyl peptidase-4 inhibitors, glucagon-like peptide-1 receptor agonists (GLP-1 RAs) or sodium glucose cotransporter 2 (SGLT-2) inhibitors as a treatment for NAFLD or NASH [29, 30, 104], as shown in Table 1. Among these newer anti-hyperglycaemic drugs, GLP-1 RAs seem to exert the most promising beneficial effects on NAFLD or NASH. A recent systematic review examining the efficacy of anti-hyperglycaemic drugs in patients with biopsy-proven or imaging-defined NAFLD with or without T2DM has supported the capability of GLP-1 RAs to reduce serum liver enzymes and improve NAFLD as detected by imaging techniques or liver histology [104]. In particular, a phase 2 RCT involving 55 UK obese patients with biopsy-proven NASH, it has been shown that patients who were randomly assigned to liraglutide $1.8 \mathrm{mg} /$ day for 48 weeks had a greater histological resolution of NASH and significant improvements in individual histologic scores of NASH compared with those receiving placebo [150]. The authors suggested that the beneficial effects of liraglutide on the histological liver endpoints were due both to its direct hepatic effect and to concomitant weight loss as liraglutide is a potent treatment to effect weight loss [150]. Importantly, liraglutide and other long-acting GLP-1 RAs have also been shown to reduce risk of adverse cardiovascular and renal outcomes in T2DM patients [124, 151]. For such reasons, if larger phase 3 RCTs confirm the promising findings of this RCT, it would be reasonable to assume that GLP-1RAs will become a treatment option in NASH, especially in those patients who are obese or have T2DM. A recent comparison of the effects of treatment with metformin versus the GLP-1 agonist 
liraglutide on the gut microbiota in patients with T2DM showed that patients taking metformin had a significant increase in the relative abundance of the bacterial genus Sutterella, whereas those taking liraglutide had a significant increase in the genus Akkermansia. Thus, these preliminary data suggest that these two anti-hyperglycaemic drugs have differential effects on the microbiome, despite the fact that both drugs are similarly effective in lowering plasma glucose concentrations [152].

A systematic review also supported the possibility that SGLT-2 inhibitors may improve liver fat content (as assessed by imaging techniques) and serum liver enzymes [104]. However, most of the RCTs testing these novel drugs are small with a short period of follow-up, and importantly, to date, there are no placebocontrolled RCTs examining the long-term effects of SGLT-2 inhibitors on histologic features of NAFLD [104]. Additionally, there is also very limited data as to the effects of this class of drugs on the gut microbiome. SGLT2 inhibitors have been shown to consistently reduce risk of major CVD events, heart failure and renal outcomes in T2DM patients [124, 153]. Moreover, among patients with systolic heart failure, the risk of worsening heart failure or of CVD mortality was lower among those patients who received the SGLT-2 inhibitor dapagliflozin than among those who received placebo; regardless of the presence or absence of T2DM [154]. Thus, this effect may represent an attractive bonus for the use of SGLT-2 inhibitors in NAFLD.

\section{Obeticholic acid and other drugs}

A number of phase 2 and phase 3 head-to-head or placebo-controlled RCTs have tested the efficacy and safety of novel drug treatments in NAFLD or NASH (Table 2). Of these, obeticholic acid is one of the more promising new agents for NASH treatment. Obeticholic acid is a selective farnesoid X receptor agonist that regulates bile acid and lipid metabolism. Obeticholic acid at a dose of $25 \mathrm{mg} /$ day has effected significant improvements in liver histology in the phase 2 FLINT clinical trial [155], as well as well as positive ad-interim results in the ongoing phase 3 REGENERATE trial [156]. Obeticholic acid was also associated with a mild decrease in body weight. However, in both trials, obeticholic acid caused marked increases in plasma LDLcholesterol levels (nearly a $40-\mathrm{mg} / \mathrm{dL}$ increase) within one month of treatment (and more than half of patients treated with obeticholic acid started statin therapy in the REGENERATE trial) $[155,156]$. Recently, it has been suggested that obeticholic may also modify the gut microbiota and produce a favourable effect on the gut microbiome [157]. In this experimental study, treatment with antibiotic (that removed normal commensal bacteria) attenuated the effect of obeticholic acid in mice. Obeticholic acid treatment markedly increased abundance of Blautia and the concentration of taurine-bound bile acid induced by the high fat diet was reduced in liver [157]. In a phase 1 RCT in man, treatment with obeticholic acid for 17 days, that suppressed bile acid synthesis, produced a reversible induction of Gram-positive bacteria that are found in 
the small intestine. There was also an increase in the representation of microbial genomic pathways involved in DNA synthesis and amino acid metabolism with obeticholic acid treatment [158].

In a 2 phase RCT, a 1-year treatment with elafibranor $120 \mathrm{mg} /$ day (i.e. a dual agonist of PPAR- $\alpha$ and PPAR- $\delta$ ) was significantly associated with a higher rate of NASH resolution than occurred in the placebo arm. Elafibranor also improved plasma LDL-cholesterol, triglyceride and glucose levels [159]. It is uncertain whether elafibranor modifies the gut microbiome, and longer-term phase 3 RCTs are also required to confirm the positive effects of elafibranor on the liver in NASH.

\section{CONCLUSIONS}

This review supports the notion that CVD is the leading cause of death in NAFLD patients and that NAFLD is closely associated with an increased risk of CVD events and other cardiac complications (i.e. cardiomyopathy, cardiac valvular calcification and arrhythmias) independent of traditional risk factors and metabolic syndrome features. Although further research is needed to draw a definitive conclusion, these observations raise the possibility that NAFLD, especially its more advanced forms, is directly involved in the pathogenesis of CVD. Recent evidence discussed here suggests that this process is mediated not only via the atherogenic dyslipidaemia occurring with features of the metabolic syndrome and NAFLD, but also through the systemic release of multiple pro-inflammatory and pro-atherogenic mediators from both the steatotic and inflamed/fibrotic liver and the intestine via changes in gut microbiota. The existing evidence to date reinforces the notion that NAFLD is a multisystem disease affecting many extra-hepatic organ systems, including the cardiovascular system. Thus, we believe that a purely "liver-centric" approach to NAFLD is not sufficient and treatment of this liver disease needs to shift to a more patient-centred, multidisciplinary teambased approach. Since more patients with NAFLD will die from CVD than from the consequences of their liver disease, we strongly believe that a careful assessment of the 10-year CVD risk is mandatory in all persons with NAFLD, together with early and aggressive treatment of all coexisting cardiometabolic risk factors.

Disclosure Statement: The Authors have no conflicts of interest to disclose.

Acknowledgments: $C D B$ is supported in part by grants from the Southampton National Institute for Health Research Biomedical Research Centre. GT is supported in part by grants from the University School of Medicine of Verona, Verona, Italy. HT is supported by the excellence initiative VASCage (Centre for Promoting Vascular Health in the Ageing Community), an R\&D K-Centre (COMET program - Competence Centers for 
Excellent Technologies) funded by the Austrian Ministry for Transport, Innovation and Technology, the Austrian Ministry for Digital and Economic Affairs and the federal states Tyrol, Salzburg and Vienna.

\section{FIGURE LEGENDS}

Figure 1. Random-effects meta-analysis on the risk of incident CVD events (fatal, non-fatal or both) associated with NAFLD. Forest plot of comparison of patients with NAFLD versus those without NAFLD. Data are derived from Targher et al. [7] (Reproduced with permission).

Figure 2. Random-effects meta-analysis on the risk of fatal and non-fatal CVD events associated with more "severe" NAFLD (defined either by presence of hepatic steatosis on imaging plus either increased serum gamma-glutamyltransferase levels or high NAFLD fibrosis score or high ${ }^{18} \mathrm{~F}$-fluoro-deoxyglucose uptake on positron emission tomography, or by increasing fibrosis stage on histology). Data are derived from Targher et al. [7] (Reproduced with permission).

Figure 3. Putative mechanisms linking NAFLD to ischaemic heart disease and other cardiac complications. Low-grade systemic inflammation plays a crucial role in the pathophysiology of cardiomyopathy and arrhythmias associated with NAFLD, and may also contribute to the development of ischaemic heart disease. In NAFLD, low-grade systemic inflammation is generated by complex inter-relationships between diet/food, the gastrointestinal tract, host factors such as genetics, the visceral adipose tissue and the liver. The liver is a major cytokine producer in NAFLD.

Figure 4. The figure schematically summarises the inter-relationships between each condition (i.e. NAFLD, T2DM and CVD) from the results of prospective cohort studies and also illustrates where randomised controlled trials have shown pioglitazone treatment acts to decrease risk of clinical outcomes.

Abbreviations: MetS, metabolic syndrome; MI, myocardial infarction; T2DM, type 2 diabetes mellitus; CVD, cardiovascular disease; NASH, nonalcoholic steatohepatitis.

\section{References}


1 Paik JM, Golabi P, Younossi Y, Mishra A, Younossi ZM. Changes in the Global Burden of Chronic Liver Diseases From 2012 to 2017: The Growing Impact of Nonalcoholic Fatty Liver Disease. Hepatology 2020.

2 Younossi ZM, Koenig AB, Abdelatif D, Fazel Y, Henry L, Wymer M. Global epidemiology of nonalcoholic fatty liver disease-Meta-analytic assessment of prevalence, incidence, and outcomes. Hepatology 2016;64:73-84.

3 Collaborators GBDCoD. Global, regional, and national age-sex-specific mortality for 282 causes of death in 195 countries and territories, 1980-2017: a systematic analysis for the Global Burden of Disease Study 2017. Lancet 2018;392:1736-88.

$4 \quad$ Byrne CD, Targher G. NAFLD: a multisystem disease. J Hepatol 2015;62:S47-64.

5 Byrne CD, Targher G. NAFLD as a driver of chronic kidney disease. J Hepatol 2020.

6 Mantovani A, Scorletti E, Mosca A, Alisi A, Byrne CD, Targher G. Complications, morbidity and mortality of nonalcoholic fatty liver disease. Metabolism 2020:154170.

7 Targher G, Byrne CD, Lonardo A, Zoppini G, Barbui C. Non-alcoholic fatty liver disease and risk of incident cardiovascular disease: A meta-analysis. J Hepatol 2016;65:589-600.

8 Wild SH, Walker JJ, Morling JR, McAllister DA, Colhoun HM, Farran B, et al. Cardiovascular Disease, Cancer, and Mortality Among People With Type 2 Diabetes and Alcoholic or Nonalcoholic Fatty Liver Disease Hospital Admission. Diabetes Care 2018;41:341-7.

9 Targher G, Day CP, Bonora E. Risk of cardiovascular disease in patients with nonalcoholic fatty liver disease. N Engl J Med 2010;363:1341-50.

10 Adams LA, Anstee QM, Tilg H, Targher G. Non-alcoholic fatty liver disease and its relationship with cardiovascular disease and other extrahepatic diseases. Gut 2017;66:1138-53.

11 Zhou YY, Zhou XD, Wu SJ, Fan DH, Van Poucke S, Chen YP, et al. Nonalcoholic fatty liver disease contributes to subclinical atherosclerosis: A systematic review and metaanalysis. Hepatol Commun 2018;2:376-92.

12 Chang Y, Ryu S, Sung KC, Cho YK, Sung E, Kim HN, et al. Alcoholic and nonalcoholic fatty liver disease and associations with coronary artery calcification: evidence from the Kangbuk Samsung Health Study. Gut 2019;68:1667-75.

13 Mantovani A, Ballestri S, Lonardo A, Targher G. Cardiovascular Disease and Myocardial Abnormalities in Nonalcoholic Fatty Liver Disease. Dig Dis Sci 2016;61:1246-67.

14 Lee SB, Park GM, Lee JY, Lee BU, Park JH, Kim BG, et al. Association between nonalcoholic fatty liver disease and subclinical coronary atherosclerosis: An observational cohort study. J Hepatol 2018;68:1018-24.

15 Paik JM, Henry L, De Avila L, Younossi E, Racila A, Younossi ZM. Mortality Related to Nonalcoholic Fatty Liver Disease Is Increasing in the United States. Hepatol Commun 2019;3:1459-71.

16 Hagstrom H, Nasr P, Ekstedt M, Hammar U, Stal P, Hultcrantz R, et al. Fibrosis stage but not NASH predicts mortality and time to development of severe liver disease in biopsyproven NAFLD. J Hepatol 2017;67:1265-73.

17 Taylor RS, Taylor RJ, Bayliss S, Hagstrom H, Nasr P, Schattenberg JM, et al. Association Between Fibrosis Stage and Outcomes of Patients with Non-Alcoholic Fatty Liver Disease: a Systematic Review and Meta-Analysis. Gastroenterology 2020.

18 Vilar-Gomez E, Calzadilla-Bertot L, Wai-Sun Wong V, Castellanos M, Aller-de la Fuente R, Metwally M, et al. Fibrosis Severity as a Determinant of Cause-Specific Mortality in Patients With Advanced Nonalcoholic Fatty Liver Disease: A Multi-National Cohort Study. Gastroenterology 2018;155:443-57 e17. 
19 Henson JB, Simon TG, Kaplan A, Osganian S, Masia R, Corey KE. Advanced fibrosis is associated with incident cardiovascular disease in patients with non-alcoholic fatty liver disease. Aliment Pharmacol Ther 2020.

20 Hagstrom H, Nasr P, Ekstedt M, Hammar U, Stal P, Askling J, et al. Cardiovascular risk factors in non-alcoholic fatty liver disease. Liver Int 2019;39:197-204.

21 Sinn DH, Kang D, Chang Y, Ryu S, Cho SJ, Paik SW, et al. Non-alcoholic fatty liver disease and the incidence of myocardial infarction: A cohort study. J Gastroenterol Hepatol 2019.

22 Labenz C, Huber Y, Michel M, Nagel M, Galle PR, Kostev K, et al. Impact of NAFLD on the Incidence of Cardiovascular Diseases in a Primary Care Population in Germany. Dig Dis Sci 2019.

23 Alexander M, Loomis AK, van der Lei J, Duarte-Salles T, Prieto-Alhambra D, Ansell $\mathrm{D}$, et al. Non-alcoholic fatty liver disease and risk of incident acute myocardial infarction and stroke: findings from matched cohort study of 18 million European adults. BMJ 2019;367:I5367.

24 Henson JB, Roden M, Targher G, Corey KE. Is NAFLD Not a Risk Factor for Cardiovascular Disease: Not Yet Time for a Change of Heart. Hepatology 2020.

25 Sinn DH, Kang D, Chang Y, Ryu S, Gu S, Kim H, et al. Non-alcoholic fatty liver disease and progression of coronary artery calcium score: a retrospective cohort study. Gut 2017;66:323-9.

26 Sinn DH, Cho SJ, Gu S, Seong D, Kang D, Kim H, et al. Persistent Nonalcoholic Fatty Liver Disease Increases Risk for Carotid Atherosclerosis. Gastroenterology 2016;151:4818 e1.

27 Anstee QM, Mantovani A, Tilg H, Targher G. Risk of cardiomyopathy and cardiac arrhythmias in patients with nonalcoholic fatty liver disease. Nat Rev Gastroenterol Hepatol 2018;15:425-39.

28 Mantovani A, Dauriz M, Sandri D, Bonapace S, Zoppini G, Tilg H, et al. Association between non-alcoholic fatty liver disease and risk of atrial fibrillation in adult individuals: An updated meta-analysis. Liver Int 2019;39:758-69.

29 European Association for the Study of the L, European Association for the Study of D, European Association for the Study of O. EASL-EASD-EASO Clinical Practice Guidelines for the management of non-alcoholic fatty liver disease. J Hepatol 2016;64:1388-402.

30 Chalasani N, Younossi Z, Lavine JE, Charlton M, Cusi K, Rinella M, et al. The diagnosis and management of nonalcoholic fatty liver disease: Practice guidance from the American Association for the Study of Liver Diseases. Hepatology 2018;67:328-57.

31 Choudhary NS, Duseja A. Screening of Cardiovascular Disease in Nonalcoholic Fatty Liver Disease: Whom and How? J Clin Exp Hepatol 2019;9:506-14.

32 Lonardo A, Sookoian S, Pirola CJ, Targher G. Non-alcoholic fatty liver disease and risk of cardiovascular disease. Metabolism 2016;65:1136-50.

33 Labenz C, Prochaska JH, Huber Y, Nagel M, Straub BK, Wild P, et al. Cardiovascular Risk Categories in Patients With Nonalcoholic Fatty Liver Disease and the Role of LowDensity Lipoprotein Cholesterol. Hepatol Commun 2019;3:1472-81.

34 Treeprasertsuk S, Leverage S, Adams LA, Lindor KD, St Sauver J, Angulo P. The Framingham risk score and heart disease in nonalcoholic fatty liver disease. Liver Int 2012;32:945-50.

35 Lonardo A, Nascimbeni F, Ballestri S, Fairweather D, Win S, Than TA, et al. Sex Differences in Nonalcoholic Fatty Liver Disease: State of the Art and Identification of Research Gaps. Hepatology 2019;70:1457-69.

36 Menotti A, Puddu PE. Can we still learn from the Seven Countries Study? Curr Opin Lipidol 2018;29:313-7. 
37 Dunn W, Xu R, Wingard DL, Rogers C, Angulo P, Younossi ZM, et al. Suspected nonalcoholic fatty liver disease and mortality risk in a population-based cohort study. Am $\mathrm{J}$ Gastroenterol 2008;103:2263-71.

38 Spence JD, Pilote L. Importance of sex and gender in atherosclerosis and cardiovascular disease. Atherosclerosis 2015;241:208-10.

39 Yang JD, Abdelmalek MF, Guy CD, Gill RM, Lavine JE, Yates K, et al. Patient Sex, Reproductive Status, and Synthetic Hormone Use Associate With Histologic Severity of Nonalcoholic Steatohepatitis. Clin Gastroenterol Hepatol 2017;15:127-31 e2.

40 Allen AM, Therneau TM, Mara KC, Larson JJ, Watt KD, Hayes SN, et al. Women With Nonalcoholic Fatty Liver Disease Lose Protection Against Cardiovascular Disease: A Longitudinal Cohort Study. Am J Gastroenterol 2019;114:1764-71.

41 Stahl EP, Dhindsa DS, Lee SK, Sandesara PB, Chalasani NP, Sperling LS. Nonalcoholic Fatty Liver Disease and the Heart: JACC State-of-the-Art Review. J Am Coll Cardiol 2019;73:948-63.

42 Dongiovanni P, Stender S, Pietrelli A, Mancina RM, Cespiati A, Petta S, et al. Causal relationship of hepatic fat with liver damage and insulin resistance in nonalcoholic fatty liver. J Intern Med 2018;283:356-70.

43 van der Poorten D, Samer CF, Ramezani-Moghadam M, Coulter S, Kacevska M, Schrijnders D, et al. Hepatic fat loss in advanced nonalcoholic steatohepatitis: are alterations in serum adiponectin the cause? Hepatology 2013;57:2180-8.

44 Tilg $\mathrm{H}$, Moschen AR. Evolution of inflammation in nonalcoholic fatty liver disease: the multiple parallel hits hypothesis. Hepatology 2010;52:1836-46.

45 Krenkel O, Tacke F. Liver macrophages in tissue homeostasis and disease. Nat Rev Immunol 2017;17:306-21.

46 Lonardo A, Nascimbeni F, Mantovani A, Targher G. Hypertension, diabetes, atherosclerosis and NASH: Cause or consequence? J Hepatol 2018;68:335-52.

47 Widjaja AA, Singh BK, Adami E, Viswanathan S, Dong J, D'Agostino GA, et al. Inhibiting Interleukin 11 Signaling Reduces Hepatocyte Death and Liver Fibrosis, Inflammation, and Steatosis in Mouse Models of Nonalcoholic Steatohepatitis. Gastroenterology 2019;157:777-92 e14.

48 Svegliati-Baroni G, Pierantonelli I, Torquato P, Marinelli R, Ferreri C, Chatgilialoglu $\mathrm{C}$, et al. Lipidomic biomarkers and mechanisms of lipotoxicity in non-alcoholic fatty liver disease. Free Radic Biol Med 2019;144:293-309.

49 Schuster S, Cabrera D, Arrese M, Feldstein AE. Triggering and resolution of inflammation in NASH. Nat Rev Gastroenterol Hepatol 2018;15:349-64.

50 Musso G, Cassader M, Paschetta E, Gambino R. Bioactive Lipid Species and Metabolic Pathways in Progression and Resolution of Nonalcoholic Steatohepatitis. Gastroenterology 2018;155:282-302 e8.

51 Luukkonen PK, Sadevirta S, Zhou Y, Kayser B, Ali A, Ahonen L, et al. Saturated Fat Is More Metabolically Harmful for the Human Liver Than Unsaturated Fat or Simple Sugars. Diabetes Care 2018;41:1732-9.

52 Mantovani A, Bonapace S, Lunardi G, Canali G, Dugo C, Vinco G, et al. Associations between specific plasma ceramides and severity of coronary-artery stenosis assessed by coronary angiography. Diabetes Metab 2019.

53 Ozcan U, Cao Q, Yilmaz E, Lee AH, Iwakoshi NN, Ozdelen E, et al. Endoplasmic reticulum stress links obesity, insulin action, and type 2 diabetes. Science 2004;306:457-61. 54 Erbay E, Babaev VR, Mayers JR, Makowski L, Charles KN, Snitow ME, et al. Reducing endoplasmic reticulum stress through a macrophage lipid chaperone alleviates atherosclerosis. Nat Med 2009;15:1383-91. 
55 Dongiovanni P, Meroni M, Baselli G, Mancina RM, Ruscica M, Longo M, et al. PCSK7 gene variation bridges atherogenic dyslipidemia with hepatic inflammation in NAFLD patients. J Lipid Res 2019;60:1144-53.

56 Fricker ZP, Pedley A, Massaro JM, Vasan RS, Hoffmann U, Benjamin EJ, et al. Liver Fat Is Associated With Markers of Inflammation and Oxidative Stress in Analysis of Data From the Framingham Heart Study. Clin Gastroenterol Hepatol 2019;17:1157-64 e4.

57 Jiang $F$, Chen Q, Wang W, Ling Y, Yan Y, Xia P. Hepatocyte-derived extracellular vesicles promote endothelial inflammation and atherogenesis via microRNA-1. J Hepatol 2020;72:156-66.

58 Brouwers M, Simons N, Stehouwer CDA, Isaacs A. Non-alcoholic fatty liver disease and cardiovascular disease: assessing the evidence for causality. Diabetologia 2020;63:253-60.

59 Lonardo A, Ballestri S, Targher G. "Not all forms of NAFLD were created equal". Do metabolic syndrome-related NAFLD and PNPLA3-related NAFLD exert a variable impact on the risk of early carotid atherosclerosis? Atherosclerosis 2017;257:253-5.

60 Simon TG, Trejo MEP, McClelland R, Bradley R, Blaha MJ, Zeb I, et al. Circulating Interleukin-6 is a biomarker for coronary atherosclerosis in nonalcoholic fatty liver disease: Results from the Multi-Ethnic Study of Atherosclerosis. Int J Cardiol 2018;259:198-204.

61 Mohamed-Ali V, Goodrick S, Rawesh A, Katz DR, Miles JM, Yudkin JS, et al. Subcutaneous adipose tissue releases interleukin-6, but not tumor necrosis factor-alpha, in vivo. J Clin Endocrinol Metab 1997;82:4196-200.

62 Moschen AR, Molnar C, Geiger S, Graziadei I, Ebenbichler CF, Weiss H, et al. Antiinflammatory effects of excessive weight loss: potent suppression of adipose interleukin 6 and tumour necrosis factor alpha expression. Gut 2010;59:1259-64.

63 Moschen AR, Molnar C, Enrich B, Geiger S, Ebenbichler CF, Tilg H. Adipose and liver expression of interleukin (IL)-1 family members in morbid obesity and effects of weight loss. Mol Med 2011;17:840-5.

64 Schweiger M, Romauch M, Schreiber R, Grabner GF, Hutter S, Kotzbeck P, et al. Pharmacological inhibition of adipose triglyceride lipase corrects high-fat diet-induced insulin resistance and hepatosteatosis in mice. Nat Commun 2017;8:14859.

65 Lovric A, Graner M, Bjornson E, Arif M, Benfeitas R, Nyman K, et al. Characterization of different fat depots in NAFLD using inflammation-associated proteome, lipidome and metabolome. Sci Rep 2018;8:14200.

66 Lazzerini PE, Capecchi PL, Laghi-Pasini F. Systemic inflammation and arrhythmic risk: lessons from rheumatoid arthritis. Eur Heart J 2017;38:1717-27.

67 Monnerat G, Alarcon ML, Vasconcellos LR, Hochman-Mendez C, Brasil G, Bassani $\mathrm{RA}$, et al. Macrophage-dependent IL-1beta production induces cardiac arrhythmias in diabetic mice. Nat Commun 2016;7:13344.

68 Wu N, Xu B, Xiang Y, Wu L, Zhang Y, Ma X, et al. Association of inflammatory factors with occurrence and recurrence of atrial fibrillation: a meta-analysis. Int $\mathrm{J}$ Cardiol 2013;169:62-72.

69 Ridker PM, Everett BM, Thuren T, MacFadyen JG, Chang WH, Ballantyne C, et al. Antiinflammatory Therapy with Canakinumab for Atherosclerotic Disease. N Engl J Med 2017;377:1119-31.

70 Kouvas N, Kontogiannis C, Georgiopoulos G, Spartalis M, Tsilimigras DI, Spartalis E, et al. The complex crosstalk between inflammatory cytokines and ventricular arrhythmias. Cytokine 2018;111:171-7.

71 Aschar-Sobbi R, Izaddoustdar F, Korogyi AS, Wang Q, Farman GP, Yang F, et al. Increased atrial arrhythmia susceptibility induced by intense endurance exercise in mice requires TNFalpha. Nat Commun 2015;6:6018. 
72 Chang SL, Hsiao YW, Tsai YN, Lin SF, Liu SH, Lin YJ, et al. Interleukin-17 enhances cardiac ventricular remodeling via activating MAPK pathway in ischemic heart failure. J Mol Cell Cardiol 2018;122:69-79.

73 Fernandez-Sada E, Torres-Quintanilla A, Silva-Platas C, Garcia N, Willis BC, Rodriguez-Rodriguez C, et al. Proinflammatory Cytokines Are Soluble Mediators Linked with Ventricular Arrhythmias and Contractile Dysfunction in a Rat Model of Metabolic Syndrome. Oxid Med Cell Longev 2017;2017:7682569.

74 Backhed F, Ding H, Wang T, Hooper LV, Koh GY, Nagy A, et al. The gut microbiota as an environmental factor that regulates fat storage. Proc Natl Acad Sci $U S A$ 2004;101:15718-23.

75 Li Z, Yang S, Lin H, Huang J, Watkins PA, Moser AB, et al. Probiotics and antibodies to TNF inhibit inflammatory activity and improve nonalcoholic fatty liver disease. Hepatology 2003;37:343-50.

76 Loomba R, Seguritan V, Li W, Long T, Klitgord N, Bhatt A, et al. Gut MicrobiomeBased Metagenomic Signature for Non-invasive Detection of Advanced Fibrosis in Human Nonalcoholic Fatty Liver Disease. Cell Metab 2017;25:1054-62 e5.

77 Caussy C, Tripathi A, Humphrey G, Bassirian S, Singh S, Faulkner C, et al. A gut microbiome signature for cirrhosis due to nonalcoholic fatty liver disease. Nat Commun 2019;10:1406.

78 Schwimmer JB, Johnson JS, Angeles JE, Behling C, Belt PH, Borecki I, et al. Microbiome Signatures Associated With Steatohepatitis and Moderate to Severe Fibrosis in Children With Nonalcoholic Fatty Liver Disease. Gastroenterology 2019;157:1109-22.

79 Del Chierico F, Nobili V, Vernocchi P, Russo A, De Stefanis C, Gnani D, et al. Gut microbiota profiling of pediatric nonalcoholic fatty liver disease and obese patients unveiled by an integrated meta-omics-based approach. Hepatology 2017;65:451-64.

80 Da Silva HE, Teterina A, Comelli EM, Taibi A, Arendt BM, Fischer SE, et al. Nonalcoholic fatty liver disease is associated with dysbiosis independent of body mass index and insulin resistance. Sci Rep 2018;8:1466.

81 lino C, Endo T, Mikami K, Hasegawa T, Kimura M, Sawada N, et al. Significant decrease in Faecalibacterium among gut microbiota in nonalcoholic fatty liver disease: a large BMI- and sex-matched population study. Hepatol Int 2019;13:748-56.

82 Zhang $Y$, Xu J, Wang X, Ren X, Liu Y. Changes of intestinal bacterial microbiota in coronary heart disease complicated with nonalcoholic fatty liver disease. BMC Genomics 2019;20:862.

83 Hoyles L, Fernandez-Real JM, Federici M, Serino M, Abbott J, Charpentier J, et al. Molecular phenomics and metagenomics of hepatic steatosis in non-diabetic obese women. Nat Med 2018;24:1070-80.

84 Caussy C, Hsu C, Lo MT, Liu A, Bettencourt R, Ajmera VH, et al. Link between gutmicrobiome derived metabolite and shared gene-effects with hepatic steatosis and fibrosis in NAFLD. Hepatology 2018;68:918-32.

85 Sookoian S, Salatino A, Castano GO, Landa MS, Fijalkowky C, Garaycoechea M, et al. Intrahepatic bacterial metataxonomic signature in non-alcoholic fatty liver disease. Gut 2020.

86 Carpino G, Del Ben M, Pastori D, Carnevale R, Baratta F, Overi D, et al. Increased liver localization of lipopolysaccharides in human and experimental non-alcoholic fatty liver disease. Hepatology 2019.

87 Scorletti E, Afolabi PR, Miles EA, Smith DE, Almehmadi A, Alshathry A, et al. Synbiotic Alters Fecal Microbiomes, but not Liver Fat or Fibrosis, in a Randomized Trial of Patients With Non-alcoholic Fatty Liver Disease. Gastroenterology 2020. 
88 Koeth RA, Lam-Galvez BR, Kirsop J, Wang Z, Levison BS, Gu X, et al. I-Carnitine in omnivorous diets induces an atherogenic gut microbial pathway in humans. J Clin Invest 2019;129:373-87.

89 Wang Z, Bergeron N, Levison BS, Li XS, Chiu S, Jia X, et al. Impact of chronic dietary red meat, white meat, or non-meat protein on trimethylamine $\mathrm{N}$-oxide metabolism and renal excretion in healthy men and women. Eur Heart J 2019;40:583-94.

90 Wang Z, Klipfell E, Bennett BJ, Koeth R, Levison BS, Dugar B, et al. Gut flora metabolism of phosphatidylcholine promotes cardiovascular disease. Nature 2011;472:5763.

91 Tang WH, Wang Z, Levison BS, Koeth RA, Britt EB, Fu X, et al. Intestinal microbial metabolism of phosphatidylcholine and cardiovascular risk. N Engl J Med 2013;368:157584.

92 Schiattarella GG, Sannino A, Toscano E, Giugliano G, Gargiulo G, Franzone A, et al. Gut microbe-generated metabolite trimethylamine-N-oxide as cardiovascular risk biomarker: a systematic review and dose-response meta-analysis. Eur Heart J 2017;38:2948-56.

93 Qi J, You T, Li J, Pan T, Xiang L, Han Y, et al. Circulating trimethylamine N-oxide and the risk of cardiovascular diseases: a systematic review and meta-analysis of 11 prospective cohort studies. J Cell Mol Med 2018;22:185-94.

94 Wu C, Xue F, Lian Y, Zhang J, Wu D, Xie N, et al. Relationship between elevated plasma trimethylamine N-oxide levels and increased stroke injury. Neurology 2020;94:e667e77.

95 Roncal C, Martinez-Aguilar E, Orbe J, Ravassa S, Fernandez-Montero A, SaenzPipaon G, et al. Trimethylamine-N-Oxide (TMAO) Predicts Cardiovascular Mortality in Peripheral Artery Disease. Sci Rep 2019;9:15580.

96 Chen YM, Liu Y, Zhou RF, Chen XL, Wang C, Tan XY, et al. Associations of gutflora-dependent metabolite trimethylamine-N-oxide, betaine and choline with non-alcoholic fatty liver disease in adults. Sci Rep 2016;6:19076.

97 Zhu W, Gregory JC, Org E, Buffa JA, Gupta N, Wang Z, et al. Gut Microbial Metabolite TMAO Enhances Platelet Hyperreactivity and Thrombosis Risk. Cell 2016;165:111-24.

98 Roberts AB, Gu X, Buffa JA, Hurd AG, Wang Z, Zhu W, et al. Development of a gut microbe-targeted nonlethal therapeutic to inhibit thrombosis potential. Nat Med 2018;24:1407-17.

99 Reiner MF, Muller D, Gobbato S, Stalder O, Limacher A, Bonetti NR, et al. Gut microbiota-dependent trimethylamine-N-oxide (TMAO) shows a U-shaped association with mortality but not with recurrent venous thromboembolism. Thromb Res 2019;174:40-7.

100 Meng G, Zhou X, Wang M, Zhou L, Wang Z, Wang M, et al. Gut microbe-derived metabolite trimethylamine $\mathrm{N}$-oxide activates the cardiac autonomic nervous system and facilitates ischemia-induced ventricular arrhythmia via two different pathways. EBioMedicine 2019;44:656-64.

101 Chen S, Henderson A, Petriello MC, Romano KA, Gearing M, Miao J, et al. Trimethylamine N-Oxide Binds and Activates PERK to Promote Metabolic Dysfunction. Cell Metab 2019;30:1141-51 e5.

102 Zhang X, Li Y, Yang P, Liu X, Lu L, Chen Y, et al. Trimethylamine-N-Oxide Promotes Vascular Calcification Through Activation of NLRP3 (Nucleotide-Binding Domain, LeucineRich-Containing Family, Pyrin Domain-Containing-3) Inflammasome and NF-kappaB (Nuclear Factor kappaB) Signals. Arterioscler Thromb Vasc Biol 2020;40:751-65.

103 Mechanick JI, Apovian C, Brethauer S, Garvey WT, Joffe AM, Kim J, et al. Clinical Practice Guidelines for the Perioperative Nutrition, Metabolic, and Nonsurgical Support of Patients Undergoing Bariatric Procedures - 2019 Update: Cosponsored by American Association of Clinical Endocrinologists/American College of Endocrinology, the Obesity Society, American Society for Metabolic \& Bariatric Surgery, Obesity Medicine Association, 
and American Society of Anesthesiologists - Executive Summary. Endocr Pract 2019;25:1346-59.

104 Mantovani A, Byrne CD, Scorletti E, Mantzoros CS, Targher G. Efficacy and safety of anti-hyperglycaemic drugs in patients with non-alcoholic fatty liver disease with or without diabetes: An updated systematic review of randomized controlled trials. Diabetes Metab 2020.

105 Targher G, Lonardo A, Byrne CD. Nonalcoholic fatty liver disease and chronic vascular complications of diabetes mellitus. Nat Rev Endocrinol 2018;14:99-114.

106 Mantovani A, Byrne CD, Bonora E, Targher G. Nonalcoholic Fatty Liver Disease and Risk of Incident Type 2 Diabetes: A Meta-analysis. Diabetes Care 2018;41:372-82.

107 Lonardo A, Lugari S, Ballestri S, Nascimbeni F, Baldelli E, Maurantonio M. A round trip from nonalcoholic fatty liver disease to diabetes: molecular targets to the rescue? Acta Diabetol 2019;56:385-96.

108 de Groot PF, Frissen MN, de Clercq NC, Nieuwdorp M. Fecal microbiota transplantation in metabolic syndrome: History, present and future. Gut Microbes 2017;8:253-67.

109 Smits LP, Kootte RS, Levin E, Prodan A, Fuentes S, Zoetendal EG, et al. Effect of Vegan Fecal Microbiota Transplantation on Carnitine- and Choline-Derived Trimethylamine$\mathrm{N}$-Oxide Production and Vascular Inflammation in Patients With Metabolic Syndrome. J Am Heart Assoc 2018;7.

110 Tontonoz P, Spiegelman BM. Fat and beyond: the diverse biology of PPARgamma. Annu Rev Biochem 2008;77:289-312.

111 Ahmadian M, Suh JM, Hah N, Liddle C, Atkins AR, Downes M, et al. PPARgamma signaling and metabolism: the good, the bad and the future. Nat Med 2013;19:557-66.

112 DeFronzo RA, Tripathy D, Schwenke DC, Banerji M, Bray GA, Buchanan TA, et al. Pioglitazone for diabetes prevention in impaired glucose tolerance. $\mathrm{N}$ Engl J Med 2011;364:1104-15.

113 Sung KC, Wild SH, Byrne CD. Development of new fatty liver, or resolution of existing fatty liver, over five years of follow-up, and risk of incident hypertension. J Hepatol 2014;60:1040-5.

114 Preis SR, Hwang SJ, Coady S, Pencina MJ, D'Agostino RB, Sr., Savage PJ, et al. Trends in all-cause and cardiovascular disease mortality among women and men with and without diabetes mellitus in the Framingham Heart Study, 1950 to 2005. Circulation 2009;119:1728-35.

115 Haffner SM, Lehto S, Ronnemaa T, Pyorala K, Laakso M. Mortality from coronary heart disease in subjects with type 2 diabetes and in nondiabetic subjects with and without prior myocardial infarction. N Engl J Med 1998;339:229-34.

116 Beckman JA, Creager MA, Libby P. Diabetes and atherosclerosis: epidemiology, pathophysiology, and management. JAMA 2002;287:2570-81.

117 Dormandy JA, Charbonnel B, Eckland DJ, Erdmann E, Massi-Benedetti M, Moules $\mathrm{IK}$, et al. Secondary prevention of macrovascular events in patients with type 2 diabetes in the PROactive Study (PROspective pioglitAzone Clinical Trial In macroVascular Events): a randomised controlled trial. Lancet 2005;366:1279-89.

118 Erdmann E, Dormandy JA, Charbonnel B, Massi-Benedetti M, Moules IK, Skene AM, et al. The effect of pioglitazone on recurrent myocardial infarction in 2,445 patients with type 2 diabetes and previous myocardial infarction: results from the PROactive (PROactive 05) Study. J Am Coll Cardiol 2007;49:1772-80.

119 Wilcox R, Bousser MG, Betteridge DJ, Schernthaner G, Pirags V, Kupfer S, et al. Effects of pioglitazone in patients with type 2 diabetes with or without previous stroke: results from PROactive (PROspective pioglitAzone Clinical Trial In macroVascular Events 04). Stroke 2007;38:865-73. 
120 Lincoff AM, Wolski K, Nicholls SJ, Nissen SE. Pioglitazone and risk of cardiovascular events in patients with type 2 diabetes mellitus: a meta-analysis of randomized trials. JAMA 2007;298:1180-8.

121 Liao HW, Saver JL, Wu YL, Chen TH, Lee M, Ovbiagele B. Pioglitazone and cardiovascular outcomes in patients with insulin resistance, pre-diabetes and type 2 diabetes: a systematic review and meta-analysis. BMJ Open 2017;7:e013927.

122 Kernan WN, Viscoli CM, Furie KL, Young LH, Inzucchi SE, Gorman M, et al. Pioglitazone after Ischemic Stroke or Transient Ischemic Attack. N Engl J Med 2016;374:1321-31.

123 Kernan WN, Viscoli CM, Dearborn JL, Kent DM, Conwit R, Fayad P, et al. Targeting Pioglitazone Hydrochloride Therapy After Stroke or Transient Ischemic Attack According to Pretreatment Risk for Stroke or Myocardial Infarction. JAMA Neurol 2017;74:1319-27.

124 Zhu J, Yu X, Zheng Y, Li J, Wang Y, Lin Y, et al. Association of glucose-lowering medications with cardiovascular outcomes: an umbrella review and evidence map. Lancet Diabetes Endocrinol 2020;8:192-205.

125 Cusi K, Orsak B, Bril F, Lomonaco R, Hecht J, Ortiz-Lopez C, et al. Long-Term Pioglitazone Treatment for Patients With Nonalcoholic Steatohepatitis and Prediabetes or Type 2 Diabetes Mellitus: A Randomized Trial. Ann Intern Med 2016;165:305-15.

126 Sanyal AJ, Chalasani N, Kowdley KV, McCullough A, Diehl AM, Bass NM, et al. Pioglitazone, vitamin $E$, or placebo for nonalcoholic steatohepatitis. $N$ Engl $J$ Med 2010;362:1675-85.

127 Belfort R, Harrison SA, Brown K, Darland C, Finch J, Hardies J, et al. A placebocontrolled trial of pioglitazone in subjects with nonalcoholic steatohepatitis. N Engl J Med 2006;355:2297-307.

128 Aithal GP, Thomas JA, Kaye PV, Lawson A, Ryder SD, Spendlove I, et al. Randomized, placebo-controlled trial of pioglitazone in nondiabetic subjects with nonalcoholic steatohepatitis. Gastroenterology 2008;135:1176-84.

129 Musso G, Cassader M, Paschetta E, Gambino R. Thiazolidinediones and Advanced Liver Fibrosis in Nonalcoholic Steatohepatitis: A Meta-analysis. JAMA Intern Med 2017;177:633-40.

130 Glen J, Floros L, Day C, Pryke R, Guideline Development G. Non-alcoholic fatty liver disease (NAFLD): summary of NICE guidance. BMJ 2016;354:i4428.

131 Corey KE, Wilson LA, Altinbas A, Yates KP, Kleiner DE, Chung RT, et al. Relationship between resolution of non-alcoholic steatohepatitis and changes in lipoprotein sub-fractions: a post-hoc analysis of the PIVENS trial. Aliment Pharmacol Ther 2019;49:1205-13.

132 Nepelska M, de Wouters T, Jacouton E, Beguet-Crespel F, Lapaque N, Dore J, et al. Commensal gut bacteria modulate phosphorylation-dependent PPARgamma transcriptional activity in human intestinal epithelial cells. Sci Rep 2017;7:43199.

133 Byndloss MX, Olsan EE, Rivera-Chavez F, Tiffany CR, Cevallos SA, Lokken KL, et al. Microbiota-activated PPAR-gamma signaling inhibits dysbiotic Enterobacteriaceae expansion. Science 2017;357:570-5.

134 Li JM, Yu R, Zhang LP, Wen SY, Wang SJ, Zhang XY, et al. Dietary fructose-induced gut dysbiosis promotes mouse hippocampal neuroinflammation: a benefit of short-chain fatty acids. Microbiome 2019;7:98.

135 DeFronzo RA, Inzucchi S, Abdul-Ghani M, Nissen SE. Pioglitazone: The forgotten, cost-effective cardioprotective drug for type 2 diabetes. Diab Vasc Dis Res 2019;16:133-43. 136 Kothari S, Dhami-Shah H, Shah SR. Antidiabetic Drugs and Statins in Nonalcoholic Fatty Liver Disease. J Clin Exp Hepatol 2019;9:723-30.

137 Kim J, Lee H, An J, Song Y, Lee CK, Kim K, et al. Alterations in Gut Microbiota by Statin Therapy and Possible Intermediate Effects on Hyperglycemia and Hyperlipidemia. Front Microbiol 2019;10:1947. 
138 Liu Y, Song X, Zhou H, Zhou X, Xia Y, Dong X, et al. Gut Microbiome Associates With Lipid-Lowering Effect of Rosuvastatin in Vivo. Front Microbiol 2018;9:530.

139 Tuteja S, Ferguson JF. Gut Microbiome and Response to Cardiovascular Drugs. Circ Genom Precis Med 2019;12:421-9.

140 Athyros VG, Alexandrides TK, Bilianou H, Cholongitas E, Doumas M, Ganotakis ES, et al. The use of statins alone, or in combination with pioglitazone and other drugs, for the treatment of non-alcoholic fatty liver disease/non-alcoholic steatohepatitis and related cardiovascular risk. An Expert Panel Statement. Metabolism 2017;71:17-32.

141 Nascimbeni F, Aron-Wisnewsky J, Pais R, Tordjman J, Poitou C, Charlotte F, et al. Statins, antidiabetic medications and liver histology in patients with diabetes with nonalcoholic fatty liver disease. BMJ Open Gastroenterol 2016;3:e000075.

142 Arnett DK, Blumenthal RS, Albert MA, Buroker AB, Goldberger ZD, Hahn EJ, et al. 2019 ACC/AHA Guideline on the Primary Prevention of Cardiovascular Disease: A Report of the American College of Cardiology/American Heart Association Task Force on Clinical Practice Guidelines. J Am Coll Cardiol 2019;74:e177-e232.

143 Sigler MA, Congdon L, Edwards KL. An Evidence-Based Review of Statin Use in Patients With Nonalcoholic Fatty Liver Disease. Clin Med Insights Gastroenterol 2018;11:1179552218787502.

144 Singh S, Singh PP, Singh AG, Murad MH, Sanchez W. Statins are associated with a reduced risk of hepatocellular cancer: a systematic review and meta-analysis. Gastroenterology 2013;144:323-32.

145 Griffin SJ, Leaver JK, Irving GJ. Impact of metformin on cardiovascular disease: a meta-analysis of randomised trials among people with type 2 diabetes. Diabetologia 2017;60:1620-9.

146 Singh S, Singh PP, Singh AG, Murad MH, Sanchez W. Anti-diabetic medications and the risk of hepatocellular cancer: a systematic review and meta-analysis. Am J Gastroenterol 2013;108:881-91; quiz 92.

147 Cunha V, Cotrim HP, Rocha R, Carvalho K, Lins-Kusterer L. Metformin in the prevention of hepatocellular carcinoma in diabetic patients: A systematic review. Ann Hepatol 2019.

148 Vallianou NG, Stratigou T, Tsagarakis S. Metformin and gut microbiota: their interactions and their impact on diabetes. Hormones (Athens) 2019;18:141-4.

149 Wu H, Esteve E, Tremaroli V, Khan MT, Caesar R, Manneras-Holm L, et al. Metformin alters the gut microbiome of individuals with treatment-naive type 2 diabetes, contributing to the therapeutic effects of the drug. Nat Med 2017;23:850-8.

150 Armstrong MJ, Gaunt P, Aithal GP, Barton D, Hull D, Parker R, et al. Liraglutide safety and efficacy in patients with non-alcoholic steatohepatitis (LEAN): a multicentre, doubleblind, randomised, placebo-controlled phase 2 study. Lancet 2016;387:679-90.

151 Kristensen SL, Rorth R, Jhund PS, Docherty KF, Sattar N, Preiss D, et al. Cardiovascular, mortality, and kidney outcomes with GLP-1 receptor agonists in patients with type 2 diabetes: a systematic review and meta-analysis of cardiovascular outcome trials. Lancet Diabetes Endocrinol 2019;7:776-85.

152 Wang Z, Saha S, Van Horn S, Thomas E, Traini C, Sathe G, et al. Gut microbiome differences between metformin- and liraglutide-treated T2DM subjects. Endocrinol Diabetes Metab 2018;1:e00009.

153 Kluger AY, Tecson KM, Lee AY, Lerma EV, Rangaswami J, Lepor NE, et al. Class effects of SGLT2 inhibitors on cardiorenal outcomes. Cardiovasc Diabetol 2019;18:99.

154 McMurray JJV, Solomon SD, Inzucchi SE, Kober L, Kosiborod MN, Martinez FA, et al. Dapagliflozin in Patients with Heart Failure and Reduced Ejection Fraction. N Engl J Med 2019;381:1995-2008. 
155 Neuschwander-Tetri BA, Loomba R, Sanyal AJ, Lavine JE, Van Natta ML, Abdelmalek MF, et al. Farnesoid $\mathrm{X}$ nuclear receptor ligand obeticholic acid for non-cirrhotic, non-alcoholic steatohepatitis (FLINT): a multicentre, randomised, placebo-controlled trial. Lancet 2015;385:956-65.

156 Younossi ZM, Ratziu V, Loomba R, Rinella M, Anstee QM, Goodman Z, et al. Obeticholic acid for the treatment of non-alcoholic steatohepatitis: interim analysis from a multicentre, randomised, placebo-controlled phase 3 trial. Lancet 2019;394:2184-96.

157 Zhang DY, Zhu L, Liu HN, Tseng YJ, Weng SQ, Liu TT, et al. The protective effect and mechanism of the FXR agonist obeticholic acid via targeting gut microbiota in nonalcoholic fatty liver disease. Drug Des Devel Ther 2019;13:2249-70.

158 Friedman ES, Li Y, Shen TD, Jiang J, Chau L, Adorini L, et al. FXR-Dependent Modulation of the Human Small Intestinal Microbiome by the Bile Acid Derivative Obeticholic Acid. Gastroenterology 2018;155:1741-52 e5.

159 Ratziu V, Harrison SA, Francque S, Bedossa P, Lehert P, Serfaty L, et al. Elafibranor, an Agonist of the Peroxisome Proliferator-Activated Receptor-alpha and -delta, Induces Resolution of Nonalcoholic Steatohepatitis Without Fibrosis Worsening. Gastroenterology 2016;150:1147-59 e5. 
Table 1. Principal phase 2 placebo-controlled or head-to-head RCTs testing the efficacy and safety of anti-hyperglycaemic drugs in patients with NAFLD or NASH.

\begin{tabular}{|l|l|l|l|l|l|l|}
\hline & $\begin{array}{l}\text { Liver } \\
\text { enzymes }\end{array}$ & $\begin{array}{l}\text { Liver } \\
\text { Fat* }\end{array}$ & $\begin{array}{l}\text { Liver } \\
\text { Inflammation§ }\end{array}$ & $\begin{array}{l}\text { Liver } \\
\text { Fibrosis§ }\end{array}$ & $\begin{array}{l}\text { NASH } \\
\text { Resolution§ }\end{array}$ & $\begin{array}{l}\text { Major Adverse } \\
\text { Effects }\end{array}$ \\
\hline Metformin & improved & improved & no effect & no effect & no effect & Gastrointestinal \\
\hline $\begin{array}{l}\text { Glitazones } \\
\text { (pioglitazone, rosiglitazone) }\end{array}$ & improved & improved & improved & improved & improved & $\begin{array}{l}\text { Weight gain (mild), oedema, heart } \\
\text { failure, bone fractures }\end{array}$ \\
\hline $\begin{array}{l}\text { GLP-1 receptor agonists } \\
\text { (liraglutide, exenatide) }\end{array}$ & improved & improved & improved & no effect & improved & Gastrointestinal \\
\hline $\begin{array}{l}\text { DPP-4 inhibitors } \\
\text { (sitagliptin, vildagliptin) }\end{array}$ & improved & no effect & unknown & unknown & unknown & Pancreatic, joint pain \\
\hline $\begin{array}{l}\text { SGLT-2 inhibitors } \\
\text { (dapaglifozin, empagliflozin, } \\
\text { canaglifozin) }\end{array}$ & improved & improved & unknown & unknown & unknown & $\begin{array}{l}\text { Genitourinary infections, } \\
\text { dehydration }\end{array}$ \\
\hline
\end{tabular}

* RCTs where liver fat was determined either by imaging methods (i.e. ultrasound and magnetic resonance imaging or spectroscopy) or by histology

$\S$ RCTs where liver inflammation, fibrosis and resolution of NASH was determined by liver biopsy

NB: The aforementioned data are derived by an updated systematic review [104] that included phase 2 head-to-head or placebo-controlled RCTs of adults or children with NAFLD or NASH, which used an European Medicines Agency-approved anti-hyperglycaemic drug for treatment of NAFLD or NASH. Only RCTs that had at least 20 patients per treatment arms of interest were included in the systematic review.

Metformin, n=6 RCTs involving a total of 573 individuals, most of whom ( $>90 \%)$ did not have T2DM, who were treated for a median of 9 months. Four RCTs had liver biopsy data.

Glitazones, $\mathrm{n}=8$ (6 pioglitazone and 2 rosiglitazone) RCTs involving a total of 828 individuals, most of whom ( $85 \%$ ) did not have T2DM, who were treated for a median of 12 months. Seven RCTs had liver biopsy data.

GLP-1 RAs, $\mathrm{n}=6$ randomized controlled trials involving a total of 396 individuals, most of whom (73\%) had T2DM, who were treated for a median of 6 months. Only one RCT had liver biopsy data (i.e. the LEAN trial).

DPP-4 inhibitors, $\mathrm{n}=4 \mathrm{RCTs}$ involving a total of 241 individuals with T2DM or prediabetes, who were treated for a median of 6 months. No RCTs with liver biopsy data.

SGLT-2 inhibitors, $n=7$ RCTs involving a total of 579 individuals (100\% had T2DM), who were treated for a median of 6 months. No RCTs with liver biopsy data.

Abbreviations: RCT, randomized controlled trial; GLP-1RAs, glucagon-like peptide-1 receptor agonists; DPP-4, dipeptidyl peptidase 4 inhibitors; SGLT-2, sodiumglucose cotransporter 2 inhibitors 
Table 2. Principal phase 2 or phase 3 placebo-controlled or head-to-head RCTs (published in the last 10 years) testing the efficacy and safety of non-antihyperglycaemic drug treatments on NAFLD or NASH (assessed either by liver biopsy or by magnetic resonance imaging) in overweight or obese adult individuals.

\begin{tabular}{|c|c|c|c|c|c|}
\hline $\begin{array}{l}\text { First author, } \\
\text { Year * }\end{array}$ & $\begin{array}{l}\text { RCT's } \\
\text { characteristics }\end{array}$ & $\begin{array}{l}\text { Intervention (group } \\
\text { sizes), Duration }\end{array}$ & $\begin{array}{l}\text { Main } \\
\text { results }\end{array}$ & $\begin{array}{l}\text { Main adverse } \\
\text { effects }\end{array}$ & $\begin{array}{l}\text { Cardiometabolic effects of the } \\
\text { 'active' drug treatment }\end{array}$ \\
\hline $\begin{array}{l}\text { Younossi ZM, } \\
2019\end{array}$ & $\begin{array}{l}\text { Multicentre, phase } 3 \text { RCT } \\
\text { of overweight or obese } \\
\text { adults with definite NASH } \\
\text { and fibrosis stages F2-F3, } \\
\text { or F1 with at least one } \\
\text { accompanying } \\
\text { comorbidity (REGENERATE } \\
\text { trial) }\end{array}$ & $\begin{array}{l}\text { A. Obeticholic acid } \\
10 \mathrm{mg} / \text { day }(\mathrm{n}=312) \text {, } \\
\text { an agonist of the } \\
\text { farnesoid } X \text { nuclear } \\
\text { receptor } \\
\text { B. Obeticholic acid } \\
25 \mathrm{mg} / \text { day }(\mathrm{n}=308) \\
\text { C. Placebo }(\mathrm{n}=311) \\
\text { Duration: } 18 \text { months } \\
\text { (planed analysis ad } \\
\text { interim) }\end{array}$ & $\begin{array}{l}\text { Fibrosis improvement ( } \geq 1 \text { stage) } \\
\text { was achieved by } 12 \% \text { of patients } \\
\text { in the placebo group, } 18 \% \text { in the } \\
\text { obeticholic acid } 10-\mathrm{mg} \text { group } \\
(\mathrm{p}=0.045) \text {, and } 23 \% \text { in the } \\
\text { obeticholic acid } 25-\mathrm{mg} \text { group } \\
(\mathrm{p}=0.0002) \text {. The NASH } \\
\text { resolution endpoint was not } \\
\text { met }(p=0.13)\end{array}$ & $\begin{array}{l}\text { Most common adverse } \\
\text { event was mild-to } \\
\text { moderate pruritus (19\% } \\
\text { in the placebo group, } \\
28 \% \text { in the obeticholic } \\
\text { acid } 10-\mathrm{mg} \text { group, and } \\
51 \% \text { in the obeticholic } \\
\text { acid } 25-\mathrm{mg} \text { group) }\end{array}$ & $\begin{array}{l}\text { Mild decrease in body weight. } \\
\text { Marked increase in plasma LDL- } \\
\text { cholesterol levels (nearly }+40 \mathrm{mg} / \mathrm{dl} \text { ) } \\
\text { after } 1 \text { month of treatment (more } \\
\text { than half of patients treated with } \\
\text { obeticholic acid started statin therapy } \\
\text { over the trial). In patients with } \\
\text { established diabetes, obeticholic acid } \\
\text { was also associated with an early } \\
\text { transient increase in plasma glucose } \\
\text { and hemoglobin A1c levels }\end{array}$ \\
\hline $\begin{array}{l}\text { Harrison SA, } \\
2019\end{array}$ & $\begin{array}{l}\text { Multicentre, phase } 2 \text { RCT } \\
\text { of US overweight or obese } \\
\text { adults with biopsy- } \\
\text { confirmed NASH (fibrosis } \\
\text { stages 1-3) and hepatic fat } \\
\text { fraction of at least } 10 \% \text { at } \\
\text { baseline when assessed by } \\
\text { MRI-proton density fat } \\
\text { fraction }\end{array}$ & $\begin{array}{l}\text { A. Resmetirom } \\
\text { (MGL-3196) } 80 \\
\mathrm{mg} / \text { day }(\mathrm{n}=84) \\
\text { B. Placebo }(\mathrm{n}=41) \\
\text { Duration: } 36 \text { weeks }\end{array}$ & $\begin{array}{l}\text { Resmetirom-treated patients } \\
\text { ( } n=78) \text { showed a relative } \\
\text { reduction of hepatic fat content } \\
\text { compared with placebo }(n=38) \\
\text { both at week } 12(-32.9 \% \\
\text { resmetirom vs. }-10.4 \% \text { placebo; } \\
\text { least squares mean difference - } \\
22.5 \%, 95 \% \mathrm{Cl}-32.9 \text { to }-12.2 ; \\
p<0.001) \text { and at week } 36 \text { (- } \\
37.3 \% \text { resmetirom [ } n=74] \text { vs. - } \\
8.5 \text { placebo [n=34]; }-28.8 \%,-42 \\
\text { to }-15.7 ; p<0.001)\end{array}$ & $\begin{array}{l}\text { Adverse events were } \\
\text { mild or moderate and } \\
\text { were well balanced } \\
\text { between the groups, } \\
\text { except for a higher } \\
\text { incidence of transient } \\
\text { mild diarrhoea and } \\
\text { nausea in the } \\
\text { resmetirom group }\end{array}$ & $\begin{array}{l}\text { Significant reductions in plasma LDL- } \\
\text { cholesterol, triglycerides, } \\
\text { apolipoprotein CIII and lipoprotein (a) } \\
\text { levels. No significant effects on body } \\
\text { weight and other metabolic } \\
\text { parameters }\end{array}$ \\
\hline $\begin{array}{l}\text { Sanyal A, } \\
2018\end{array}$ & $\begin{array}{l}\text { Multicentre, phase } 2 \text { RCT } \\
\text { of US overweight or obese } \\
\text { adults with biopsy- } \\
\text { confirmed NASH (fibrosis } \\
\text { stage 1-3), and a hepatic } \\
\text { fat fraction of at least 10\% } \\
\text { when assessed by } \\
\text { magnetic resonance } \\
\text { imaging-proton density fat } \\
\text { fraction }\end{array}$ & $\begin{array}{l}\text { A. Pegbelfermin } \\
\text { (BMS-986036) } 10 \mathrm{mg} \\
\text { once a day } \\
\text { subcutaneoulsy } \\
\text { ( } n=25) \\
\text { B. Pegbelfermin } 20 \\
\text { mg once a week } \\
\text { subcutaneoulsy } \\
(n=24) \\
\text { C. Placebo ( } n=26) \\
\text { Duration: } 16 \text { weeks }\end{array}$ & $\begin{array}{l}\text { Significant decrease in absolute } \\
\text { hepatic fat fraction in the group } \\
\text { receiving } 10 \mathrm{mg} \text { pegbelfermin } \\
\text { daily }(-6.8 \% \text { vs. }-1.3 \% ; p=0.0004) \\
\text { and in the group receiving } 20 \\
\text { mg pegbelfermin weekly }(-5.2 \% \\
\text { vs. }-1.3 \% ; p=0.008) \text { compared } \\
\text { with the placebo group }\end{array}$ & $\begin{array}{l}\text { Most adverse events } \\
\text { were mild; the most } \\
\text { common events were } \\
\text { diarrhoea in } 16 \% \text { of } \\
\text { patients treated with } \\
\text { pegbelfermin and } 8 \% \text { of } \\
\text { patients treated with } \\
\text { placebo and nausea in } \\
14 \% \text { patients treated } \\
\text { with pegbelfermin and } \\
8 \% \text { patients treated } \\
\text { with placebo }\end{array}$ & $\begin{array}{l}\text { No significant changes in body weight } \\
\text { and plasma lipid profile (although } \\
\text { plasma LDL-cholesterol levels tended } \\
\text { to improve in those treated with } \\
\text { pegbelfermin } 10 \mathrm{mg} / \text { day) between } \\
\text { treatment arms. Significant increase } \\
\text { in plasma adiponection levels in those } \\
\text { treated with pegbelfermin }\end{array}$ \\
\hline
\end{tabular}




\begin{tabular}{|c|c|c|c|c|c|}
\hline $\begin{array}{l}\text { Loomba R, } \\
2018\end{array}$ & $\begin{array}{l}\text { Multicentre, phase } 2 \text { study } \\
\text { of US overweight or obese } \\
\text { adults with biopsy- } \\
\text { confirmed NASH (fibrosis } \\
\text { stage 1-3), and a hepatic } \\
\text { fat fraction of at least } 8 \% \\
\text { when assessed by } \\
\text { magnetic resonance } \\
\text { imaging-proton density fat } \\
\text { fraction and liver stiffness } \\
\text { of at least } 2.5 \mathrm{kPa} \text {, based } \\
\text { on MRI elastography } \\
\text { measurement or historical } \\
\text { biopsy result consistent } \\
\text { with NASH and F1-F3 } \\
\text { fibrosis }\end{array}$ & $\begin{array}{l}\text { A. GS-0976 } 5 \\
\text { mg/day (an inhibitor } \\
\text { of acetyl-coenzyme } \\
\text { A carboxylase) } \\
(\mathrm{n}=46) \\
\text { B. GS-0976 } 20 \\
\mathrm{mg} / \text { day }(\mathrm{n}=46) \\
\text { C. Placebo }(\mathrm{n}=26) \\
\text { Duration: } 12 \text { weeks }\end{array}$ & $\begin{array}{l}\text { A relative decrease of at least } \\
30 \% \text { from baseline in MRI-PDFF } \\
\text { occurred in } 48 \% \text { of patients } \\
\text { given GS- } 097620 \mathrm{mg} \text { ( } \mathrm{p}=0.004 \\
\text { vs. placebo), } 23 \% \text { given GS-0976 } \\
5 \mathrm{mg}(\mathrm{p}=0.43 \text { vs. placebo), and } \\
15 \% \text { given placebo. Changes in } \\
\text { MRI elastography-measured } \\
\text { stiffness did not significantly } \\
\text { differ among the groups, but a } \\
\text { dose-dependent decrease in the } \\
\text { fibrosis marker tissue inhibitor } \\
\text { of metalloproteinase- } 1 \text { (TIMP-1) } \\
\text { levels was observed in patients } \\
\text { given GS-0976 } 20 \mathrm{mg}\end{array}$ & $\begin{array}{l}\text { GS-0976 was safe; the } \\
\text { most common adverse } \\
\text { events were nausea } \\
\text { and diarrhoea as well } \\
\text { as increase in serum } \\
\text { alkaline phosphatase } \\
\text { levels }\end{array}$ & $\begin{array}{l}\text { Significant increases in plasma } \\
\text { triglyceride and glucose levels were } \\
\text { observed ( } 16 \% \text { of GS-0976-treated } \\
\text { patients showed } \\
\text { hypertriglyceridemia }>500 \mathrm{mg} / \mathrm{dl} \text { and } \\
\text { started treatment with fibrates over } \\
\text { the trial) }\end{array}$ \\
\hline $\begin{array}{l}\text { Harrison SA, } \\
2018\end{array}$ & $\begin{array}{l}\text { Multicentre, phase } 2 \text { RCT } \\
\text { of overweight or obese } \\
\text { adults with biopsy- } \\
\text { confirmed NASH (stage 1- } \\
3 \text { fibrosis), and at least } 8 \% \\
\text { liver fat content when } \\
\text { assessed by magnetic } \\
\text { resonance imaging-proton } \\
\text { density fat fraction }\end{array}$ & $\begin{array}{l}\text { A. NGM282 } 3 \text { mg } \\
\text { once a day } \\
\text { subcutaneoulsy } \\
\text { ( } n=27) \text {, an } \\
\text { engineered FGF19 } \\
\text { analogue, } \\
\text { B. NGM282 } 6 \mathrm{mg} \\
\text { once a day } \\
\text { subcutaneoulsy } \\
(n=28) \\
\text { C. Placebo }(n=27)\end{array}$ & $\begin{array}{l}\text { At } 12 \text { weeks, } 74 \% \text { patients in the } \\
3 \text {-mg dose group and } 79 \% \text { in the } \\
6 \text {-mg dose group achieved at } \\
\text { least a } 5 \% \text { reduction in absolute } \\
\text { liver fat content measured by } \\
\text { MRI-PDFF from baseline } \\
\text { (relative risk } 10 \% \text { [ } 95 \% \mathrm{Cl} 2.6- \\
38.7] \text { vs. } 11.4 \% \text { [ } 95 \% \mathrm{Cl} 3.0- \\
43.8] \text {, respectively; } p<0.001 \text { for } \\
\text { both comparisons) vs. } 7 \% \text { in the } \\
\text { placebo group }\end{array}$ & $\begin{array}{l}\text { The most commonly } \\
(\geq 10 \%) \text { reported } \\
\text { adverse events were } \\
\text { injection site reactions, } \\
\text { diarrhoea, abdominal } \\
\text { pain and nausea }\end{array}$ & $\begin{array}{l}\text { Marked increases in plasma LDL- } \\
\text { cholesterol levels in both the } 3 \mathrm{mg} \\
\text { NGM282 group and the } 6 \mathrm{mg} \\
\text { NGM282 group. No significant effects } \\
\text { on body weight and other metabolic } \\
\text { parameters (plasma glucose, insulin } \\
\text { and hemoglobin A1c) }\end{array}$ \\
\hline & & Duration: 12 weeks & & & \\
\hline $\begin{array}{l}\text { Loomba R, } \\
2018\end{array}$ & $\begin{array}{l}\text { Multinational, phase } 2 \\
\text { RCT of overweight or } \\
\text { obese adults with biopsy- } \\
\text { confirmed NASH (fibrosis } \\
\text { stage } 2 \text { or } 3 \text { ) }\end{array}$ & $\begin{array}{l}\text { A. Selonsertib, a } \\
\text { selective inhibitor of } \\
\text { apoptosis signal- } \\
\text { regulating kinase } 1 \text {, } \\
6 \text { mg/day plus once- } \\
\text { weekly injections of } \\
125 \text { mg of } \\
\text { Simtuzumab ( } n=30) \\
\text { B. Selonsertib 18 } \\
\text { mg/day plus once- } \\
\text { weekly injections of } \\
125 \text { mg of } \\
\text { Simtuzumab ( } n=32 \text { ) }\end{array}$ & $\begin{array}{l}\text { After } 24 \text { weeks of treatment, } \\
\text { the proportion of patients with } \\
\text { a one or more stage reduction } \\
\text { in liver fibrosis in the } 18-\mathrm{mg} \\
\text { selonsertib group was } 13 \text { of } 30 \\
\text { ( } 43 \%) \text {; in the } 6 \text {-mg selonsertib } \\
\text { group, } 8 \text { of } 27 \text { ( } 30 \%) \text {; and in the } \\
\text { simtuzumab-alone group, } 2 \text { of } \\
10 \text { ( } 20 \%) \text {. Fibrosis improvement } \\
\text { was associated with reductions } \\
\text { in liver stiffness on MRI } \\
\text { elastography, collagen content }\end{array}$ & $\begin{array}{l}\text { No significant } \\
\text { differences in adverse } \\
\text { events between the } \\
\text { treatment groups; the } \\
\text { most common adverse } \\
\text { events were headache, } \\
\text { nausea and sinusitis }\end{array}$ & $\begin{array}{l}\text { Significant increases in plasma glucose } \\
\text { levels ( }>250 \mathrm{mg} / \mathrm{dl}) \text { were observed in } \\
\text { nearly } 10 \% \text { of treated patients. } \\
\text { Marked increases in plasma } \\
\text { triglycerides ( }>500 \mathrm{mg} / \mathrm{dl} \text { ) were also } \\
\text { observed in nearly } 5 \% \text { of treated } \\
\text { patients. No significant effects on } \\
\text { body weight or hemoglobin A1c levels }\end{array}$ \\
\hline
\end{tabular}




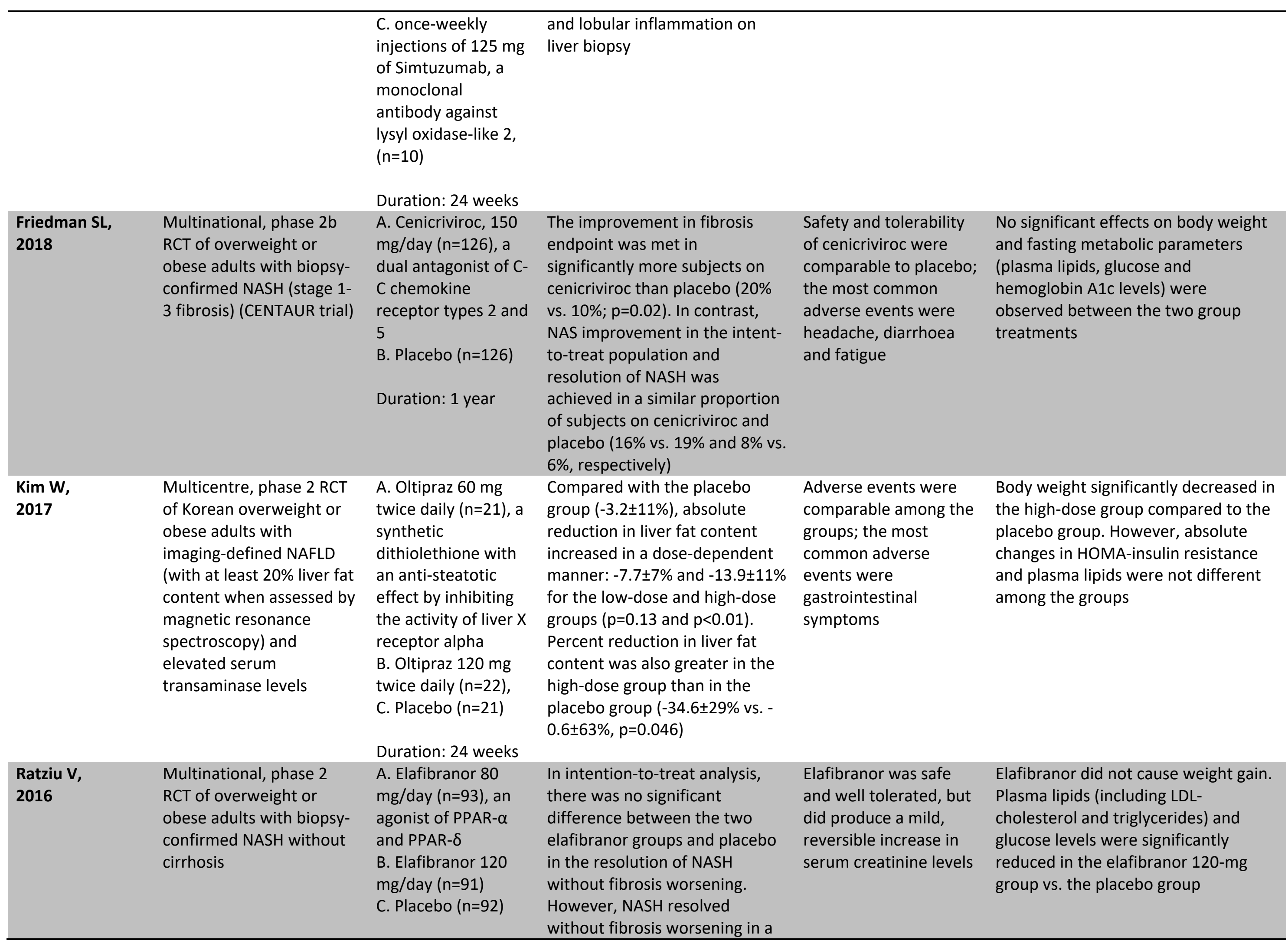




\begin{tabular}{|c|c|c|c|c|c|}
\hline & & Duration: 52 weeks & $\begin{array}{l}\text { higher proportion of patients in } \\
\text { the } 120 \text {-mg elafibranor group } \\
\text { vs. the placebo group (19\% vs. } \\
12 \% ; p=0.045 \text { ), based on a post- } \\
\text { hoc analysis for the modified } \\
\text { definition. Patients with NASH } \\
\text { resolution after receiving } \\
\text { elafibranor } 120 \text { mg had reduced } \\
\text { liver fibrosis stages compared } \\
\text { with those without NASH } \\
\text { resolution }\end{array}$ & & \\
\hline $\begin{array}{l}\text { Neuschwander- } \\
\text { Tetri BA, } 2015\end{array}$ & $\begin{array}{l}\text { Multicentre, phase } 2 \mathrm{~b} \text { RCT } \\
\text { of US overweight or obese } \\
\text { adults with biopsy- } \\
\text { confirmed NASH without } \\
\text { cirrhosis (FLINT trial) }\end{array}$ & $\begin{array}{l}\text { A. Obeticholic acid } \\
25 \mathrm{mg} / \text { day }(n=110) \\
\text { B. Placebo }(n=109) \\
\text { Duration: } 72 \text { weeks }\end{array}$ & $\begin{array}{l}45 \% \text { of patients in the } \\
\text { obeticholic acid group had } \\
\text { improved liver histology (i.e. } \\
\text { decrease in NAS score by at } \\
\text { least } 2 \text { points without } \\
\text { worsening of fibrosis) compared } \\
\text { with } 21 \% \text { of patients in the } \\
\text { placebo group ( } p=0.0002) \text {. The } \\
\text { NASH resolution endpoint was } \\
\text { not met ( } p=0.08 \text { ) }\end{array}$ & $\begin{array}{l}\text { Adverse events were } \\
\text { generally mild to } \\
\text { moderate and were } \\
\text { similar for the two } \\
\text { groups, except for } \\
\text { pruritus; } 23 \% \text { of } \\
\text { patients in the } \\
\text { obeticholic acid had } \\
\text { pruritus compared with } \\
6 \% \text { in the placebo } \\
\text { group }\end{array}$ & $\begin{array}{l}\text { Mild decrease in body weight. } \\
\text { Improvement in fasting insulin and } \\
\text { HOMA-IR values, but no significant } \\
\text { changes in plasma glucose and } \\
\text { hemoglobin A1c levels. Marked } \\
\text { increase in plasma LDL-cholesterol } \\
\text { and decrease in HDL-cholesterol } \\
\text { (already within } 3 \text { months of treatment } \\
\text { with obeticholic acid). Significant } \\
\text { increases in platelet count and serum } \\
\text { creatinine levels were also observed }\end{array}$ \\
\hline $\begin{array}{l}\text { Zein CO, } \\
2011\end{array}$ & $\begin{array}{l}\text { Multicentre, phase } 2 \text { RCT } \\
\text { of US overweight or obese } \\
\text { adults with biopsy- } \\
\text { confirmed NASH }\end{array}$ & $\begin{array}{l}\text { A. Pentoxifylline } 400 \\
\text { mg three times a } \\
\text { day }(n=26) \\
\text { B. Placebo ( } n=29) \\
\text { Duration: } 12 \text { months }\end{array}$ & $\begin{array}{l}\text { After } 1 \text { year, intention-to-treat } \\
\text { analysis showed a decrease of } \\
\geq 2 \text { points in the NAS in } 38.5 \% \text { of } \\
\text { patients on pentoxifylline vs. } \\
13.8 \% \text { of those on placebo } \\
\text { ( } p=0.036 \text { ). Pentoxifylline } \\
\text { significantly improved steatosis } \\
\text { (mean change in score -0.9 vs. - } \\
0.04 \text { with placebo) and lobular } \\
\text { inflammation (median change -1 } \\
\text { vs. } 0 \text { with placebo). Although } \\
\text { not statistically significant, } \\
\text { improvement in fibrosis was } \\
\text { observed in a greater } \\
\text { proportion ( } 35 \% \text { ) of patients on } \\
\text { pentoxifylline compared to } \\
\text { those on placebo (15\%) }\end{array}$ & $\begin{array}{l}\text { Nausea and vomiting } \\
\text { were more frequently } \\
\text { among those treated } \\
\text { with pentoxifylline }\end{array}$ & $\begin{array}{l}\text { Mild decrease in body weight. No } \\
\text { significant changes in HOMA-insulin } \\
\text { resistance, plasma glucose, lipids and } \\
\text { cytokines (i.e. plasma adiponectin and } \\
\text { tumor necrosis factor-alpha levels) }\end{array}$ \\
\hline $\begin{array}{l}\text { Van Wagner LB, } \\
2011\end{array}$ & $\begin{array}{l}\text { Single-center, phase } 2 \text { RCT } \\
\text { of US overweight or obese }\end{array}$ & $\begin{array}{l}\text { A. Pentoxifylline } 400 \\
\text { mg three times a } \\
\text { day }(n=21)\end{array}$ & $\begin{array}{l}\text { After } 12 \text { months, liver steatosis } \\
\text { and cellular ballooning } \\
\text { improved in the pentoxifylline }\end{array}$ & $\begin{array}{l}\text { Adverse events were } \\
\text { mild, most frequently } \\
\text { headache and }\end{array}$ & $\begin{array}{l}\text { No significant changes in body weight, } \\
\text { HOMA-insulin resistance, plasma } \\
\text { glucose, lipids and cytokines }\end{array}$ \\
\hline
\end{tabular}




\begin{tabular}{|c|c|c|c|c|c|}
\hline & $\begin{array}{l}\text { adults with biopsy- } \\
\text { confirmed NASH }\end{array}$ & $\begin{array}{l}\text { B. Placebo }(n=9) \\
\text { Duration: } 12 \text { months }\end{array}$ & $\begin{array}{l}\text { group }(p<0.05) \text {, whereas no } \\
\text { histological feature of NASH } \\
\text { improved with placebo }\end{array}$ & $\begin{array}{l}\text { abdominal cramps, and } \\
\text { did not differ between } \\
\text { the groups }\end{array}$ & \\
\hline $\begin{array}{l}\text { Sanyal AJ, } \\
2010\end{array}$ & $\begin{array}{l}\text { Multicentre, phase } 3 \text { RCT } \\
\text { of US overweight or obese } \\
\text { adults with biopsy- } \\
\text { confirmed NASH without } \\
\text { diabetes (PIVENS trial) }\end{array}$ & $\begin{array}{l}\text { A. Pioglitazone } 30 \\
\text { mg/day }(n=80) \\
\text { B. Vitamin E } 800 \\
\text { IU/day }(n=84) \\
\text { C. Placebo }(n=83) \\
\text { Duration: } 96 \text { weeks }\end{array}$ & $\begin{array}{l}\text { Vitamin E therapy, as compared } \\
\text { with placebo, was associated } \\
\text { with a significantly higher rate } \\
\text { of improvement in NASH ( } 43 \% \\
\text { vs. } 19 \%, p=0.001 \text { ), but the } \\
\text { difference in the rate of } \\
\text { improvement with pioglitazone } \\
\text { as compared with placebo was } \\
\text { not significant ( } 34 \% \text { and } 19 \% \text {, } \\
\text { respectively; } p=0.04) \text {. Both } \\
\text { agents were associated with } \\
\text { significant reductions in hepatic } \\
\text { steatosis and lobular } \\
\text { inflammation but not with } \\
\text { improvement in fibrosis scores } \\
\text { compared to placebo }\end{array}$ & $\begin{array}{l}\text { Adverse effects were } \\
\text { similar among the } \\
\text { three groups (except } \\
\text { for weight gain in the } \\
\text { pioglitazone group) }\end{array}$ & $\begin{array}{l}\text { Subjects who received pioglitazone } \\
\text { gained more weight than did those } \\
\text { who received vitamin E or placebo. } \\
\text { Pioglitazone also significantly } \\
\text { increased plasma HDL-cholesterol } \\
\text { levels, improved HOMA-insulin } \\
\text { resistance, decreased plasma glucose } \\
\text { levels and tended to decrease plasma } \\
\text { triglycerides compared to placebo. No } \\
\text { significant changes in body weight, } \\
\text { plasma lipids and metabolic } \\
\text { parameters were observed between } \\
\text { the vitamin E and the placebo groups }\end{array}$ \\
\hline
\end{tabular}

* The complete list of references that are included in the table are reported in the online-only supplementary material.

NB: We did not include in the table phase 3 RCTs (i.e. STELLAR 3 and STELLAR 4 trials) with selonsertib in patients with advanced fibrosis or compensated cirrhosis that were early stopped for lack of any efficacy. We did not also include in the table phase 2 RCTs that used probiotic/synbiotic supplementations, vitamin D supplementations or high-dose $\mathrm{n}-3$ polyunsaturated fatty acids.

Abbreviations: HOMA, homeostasis model assessment; NASH, nonalcoholic steatohepatitis; RCT, randomized controlled trial. 